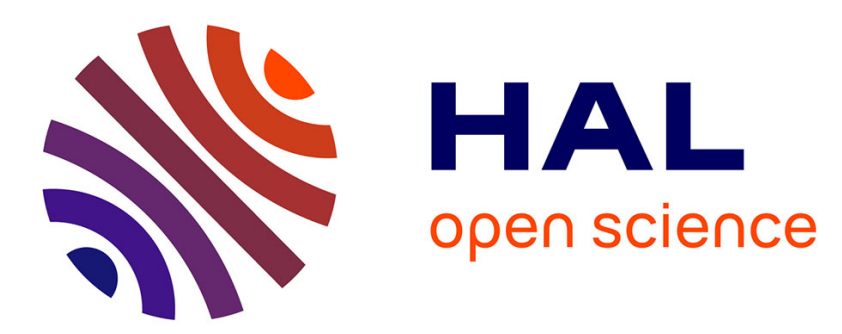

\title{
Aspects du culte dans les églises de Numidie au temps d'Augustin : un état de la question
}

\author{
Anne Michel
}

\section{To cite this version:}

Anne Michel. Aspects du culte dans les églises de Numidie au temps d'Augustin: un état de la question. Serge Lancel. Saint Augustin, la Numidie et la société de son temps, 14, Ausonius, pp.67108, 2005, Scripta Antiqua, 10.4000/books.ausonius.8103 . hal-02768336

\section{HAL Id: hal-02768336 https://hal.science/hal-02768336}

Submitted on 6 Oct 2020

HAL is a multi-disciplinary open access archive for the deposit and dissemination of scientific research documents, whether they are published or not. The documents may come from teaching and research institutions in France or abroad, or from public or private research centers.
L'archive ouverte pluridisciplinaire HAL, est destinée au dépôt et à la diffusion de documents scientifiques de niveau recherche, publiés ou non, émanant des établissements d'enseignement et de recherche français ou étrangers, des laboratoires publics ou privés. 


\title{
ASPECTS DU CULTE DANS LES ÉGLISES DE NUMIDIE AU TEMPS D’AUGUSTIN : UN ÉTAT DE LA QUESTION
}

\author{
Anne MiCHEL *
}

Les sources littéraires témoignent de l'importante activité qu'Augustin déploya à travers toute l'Afrique, après son retour en 388 , en particulier dans le vaste évêché rural d'Hippone ${ }^{1}$ qui lui avait été confié. Elles attestent aussi, dès l'époque de Cyprien de Carthage $^{2}$, l'extrême densité des sièges épiscopaux africains, surtout dans la province de Proconsulaire et dans une moindre mesure de Numidie. Les vestiges archéologiques complètent ce témoignage en révélant des aspects du culte chrétien que les sources écrites ne mentionnent que de manière allusive.

Le nombre d'édifices chrétiens connus dans la province de Numidie - entendue dans son sens ecclésiastique, c'est-à-dire en incluant les cités qui dépendaient de la Proconsulaire du point de vue civil $^{3}$ - est considérable : on ne dénombre pas moins de 207 bâtiments répartis sur 126 sites, dont 167 sur 97 sites pour la seule Numidie. Cependant l'impression de la densité de l'implantation chrétienne qui ressort de ces chiffres masque en fait la difficulté posée par l'étude de ces vestiges, qui reste largement tributaire d'études déjà anciennes. Outre les travaux effectués par les militaires français à la fin du XIXe et au début du XXe siècle, la synthèse de Stéphane Gsell ${ }^{4}$ reste aujourd'hui encore une référence obligée pour leur connaissance. Elle a été complétée par quelques fouilles menées dans les années 1930 par des membres de l'École française de Rome ${ }^{5}$, auxquelles il faut ajouter le fruit des "chantiers de charité 6 " qui ont donné lieu à des articles de synthèse sur les basiliques de l'Algérie ${ }^{7}$. Des travaux plus précis ont été entrepris par Yvonne Allais à Djemila entre 1942 et 1957, par P.-A. Février ${ }^{8}$ à la fin des années 1960 lorsqu'il était en poste à la direction des Antiquités de l'Algérie, et par J. Christern ${ }^{9}$ à Tébessa. Les quelques réflexions d'ensemble

* Université Michel de Montaigne Bordeaux 3 - Ausonius.

1 LANCEL S., Études sur la Numidie d'Hippone, 1984, p. 1085-1113 ; ID., Évêchés et cités, 1990, p. 273 $290 ;$ ID., À propos des nouvelles lettres de saint Augustin, 1982, p. 446-454.

2 Duval Y., Densité et répartition des évêchés, 1984, p. 493-521.

3 FERDI S., Augustin de retour en Afrique. 388-430, 2001, p. 20-24 sur l'organisation ecclésiastique de l'Algérie au temps d'Augustin. Seuls les édifices situés sur l'actuel territoire algérien sont pris en compte ici.

4 Gsell St., Monuments antiques, 1901; ID., Atlas Archéologique, 1911.

5 LABrousse M., Henchir Tarlist, 1938, p. 224-258 ; CAYREL P., Basilique donatiste, 1934, p. 114-142 ; COURCELle P., Ksar el-Kelb, 1936, p. 166-184.

6 BerTHIER A., LOGEART F., MARTIN M., s. d. [1942] Numidie Centrale.

7 LESCHI L., Basilique chrétienne, 1940, p. 145-167 (= LESCHI L., Études, 1957, p. 85-100) ; LASSUS J., Architecture chrétienne, 1972, p. 107-125, pl. XXXIV-XXXVII.

8 FÉVRIER P.-A., Travaux récents, 1969, p. 511-521, pl. CCXLIII-CCLXVIII ; ID., Travaux et découvertes, 1972, p. 299-324, pl. CXX-CXXVII.

9 Christern J., Tebessa, 1976. 
menées entre la fin des années 1960 et le milieu des années 1980 - sessions des cours de Ravenne consacrées à l'Afrique du Nord ${ }^{10}$, colloque sur l'inhumation privilégiée en Occident tenu à l'université de Créteil en 1984, au cours duquel l'Afrique du Nord a été évoquée à plusieurs reprises ${ }^{11}$ - restent fondées sur ces recherches de terrain plus anciennes. Il faut y ajouter encore l'étude menée dans les années 1970 par Y. Duval sur l'épigraphie martyrologique ${ }^{12}$ en Afrique du Nord, ainsi que l'inventaire des basiliques chrétiennes de l'Algérie réalisé par I. Gui dans les années 1980 et publié au début de la décennie suivante ${ }^{13}$ sous la responsabilité de N. Duval et J.-P. Caillet, qui ont permis de recenser une bonne partie des vestiges chrétiens connus jusqu'alors.

L'ancienneté globale des travaux cités, conjuguée à un état de conservation souvent précaire, rend difficile une étude précise des bâtiments : toute tentative se heurte rapidement au problème délicat posé par la datation des vestiges. Trop souvent, les édifices - notamment pour les fouilles anciennes pour lesquelles on dispose rarement de rapports complets - ont été datés, sans réelle analyse archéologique, par rapport aux découpages de l'historiographie traditionnelle, c'est-à-dire le plus souvent avant l'époque vandale, même si les travaux d'Yvette et Noël Duval ont depuis largement démontré que bien des églises furent en fait construites - ou du moins remaniées - à l'époque byzantine. Les datations les plus précises restent liées aux indications épigraphiques, avec toutes les difficultés qu'elles soulèvent, puisque les inscriptions sont surtout datées d'après la paléographie ou le formulaire épigraphique. Dans les rares cas où il est possible de proposer une datation absolue, l'inscription date généralement le support sur lequel elle se trouve (poteau ou plaque de chancel, sépulture, parfois claveau d'arc, dépôt de reliques), mais pas nécessairement le monument lui-même. Ceci est d'autant plus vrai pour les riches dépôts de reliques accompagnés de procès-verbaux détaillés de Sila ou Henchir Akrib ${ }^{14}$ qui remontent au VIe, voire au VII siècle, alors que l'église est manifestement plus ancienne. Je laisserai pourtant de côté ces églises, dans la mesure où aucun indice ne vient attester leur existence dès l'époque d'Augustin. Les autres indices chronologiques reposent parfois sur le style du décor architectural (poteaux de chancels sculptés et chapiteaux notamment), mais il n'existe encore aucun corpus détaillé étudiant l'évolution stylistique de la sculpture, exceptés le premier recensement présenté par N. Duval et P.-A. Février au congrès d'archéologie chrétienne de Barcelone en $1969^{15}$ et le travail réalisé par J. Christern à Tébessa ${ }^{16}$. Les méthodes de datation de ces édifices restent donc très aléatoires.

10 Duval N., Églises à deux absides d'Algérie, 1970, p. 190-218 ; ID., Mosaïques funéraires d'Algérie, 1970, p. 219-229 ; Février P.-A., Culte des martyrs, 1970, p. 191-215 ; ID., Sources épigraphiques et archéologiques, 1972, p. 146-150.

42.

11 FÉVRIER P.-A., Inhumation privilégiée, 1986, p. 13-23 ; DuVAL N., Inhumation privilégiée, 1986, p. 25 -

12 Duval Y., Loca Sanctorum, 1982.

13 Gui I., Duval N., Caillet J.-P., Basiliques de l'algérie, 1992.

276.

14 Duval Y., Loca sanctorum, I, n $106-111,1982$, p. 215-231 (Sila), n 126-132 (Henchir Akhrib), p. 259-

15 Duval N. et FÉVRIER P.-A, Décor des monuments chrétiens d'Afrique, 1972, p. 5-55, pl. I-XXVI.

16 Christern J., Tebessa, Wiesbaden, 1976, chap. VI, Die Bauornamentik, p. 178-215 ; IX, Stilfragen, p. 257-263 ; X, Historische und typologische Einordnung, p. 264-292. 
De fait, on ne connaît en Afrique que peu de vestiges d'édifices chrétiens urbains dont la construction remonte assurément au cours du IV e siècle ${ }^{17}$. On comprendra donc que déterminer la réalité de l'implantation monumentale chrétienne en Numidie au temps d'Augustin reste difficile. Malgré le grand nombre d'édifices conservés - au moins partiellement - en Numidie, si l'on prend en compte uniquement ceux pour lesquels on dispose d'indices, parfois ténus, d'une datation remontant au temps de saint Augustin c'est-à-dire, au sens large, entre le IV et la première moitié du ve siècle - leur nombre se réduit singulièrement. On n'en compte plus alors que 22 pour lesquels on possède des vestiges suffisants ${ }^{18}$, auxquels il faut ajouter trois sites qui ont livré des objets liés au culte chrétien, mais dont l'édifice dont ils proviennent reste inconnu ${ }^{19}$. Certes, on pourrait y ajouter ceux dont les dispositions architecturales et liturgiques sont semblables aux édifices mieux situés chronologiquement, mais on mesure combien les conclusions que l'on peut en tirer demeurent fragiles. C'est pourquoi seuls les 22 édifices signalés seront pris en compte.

Ceux-ci se répartissent sur le territoire de toute la Numidie, d'Hippone sur la côte, à Djemila, aux confins avec la Maurétanie sitifienne (fig. 1). Le hasard des fouilles et de la conservation des vestiges fait que les églises se concentrent surtout dans le Sud-Est de la Numidie ecclésiastique, autour de Tébessa (Ksar el Kelb, Henchir el Abiod, Henchir Touta, Morsott, Tébessa-Khalia, Henchir Deheb) et au centre de la province, autour de Timgad (Timgad, Henchir Guesseria, Oued Rezel, Henchir el Atech, Seriana, Henchir Bou Takrematen, Kherbet el Ousfane, Henchir el Atech, Henchir Tarlist). Il faut encore y ajouter, en Proconsulaire, Madaure, et, dans l'extrême Sud de la Numidie, Et-Toual.

On constate ainsi que les grandes cités liées à l'action d'Augustin (Hippone, Madaure et Thagaste) n'ont guère livré de vestiges archéologiques datables de l'époque de l'évêque d'Hippone. À Hippone, la cité épiscopale, parmi les sept églises qui existaient alors ${ }^{20}$, un

17 C'est ce que rappelle FÉVRIER P.-A., Approches du Maghreb romain, II, 1990, p. 27-28 : "Si l'on met à part la basilique de Castellum Tingitanum (Ch'lif) dont la date fait problème - une inscription y fait allusion à des travaux (le début ?) en 325 -, la plupart des lieux de culte intra-urbains que nous connaissions n'ont pas été construits avant la fin du IV e siècle ou au Ve siècle même. Le plus important d'entre eux est le groupe épiscopal ; mais il doit être clair qu'assez tôt d'autres lieux de culte sont apparus."

18 Hippone ; Madaure 2 et 3 ; Morsott 1 ; Tébessa ; Tébessa-Khalia 2 (triconque) ; Henchir Deheb ; Ksar el-Kelb(région de Kenchela) ; Timgad 1 ; Timgad 7 ; Henchir Guesseria et Oued Rhezel 4 (région de Chemorra) ; Kherbet el Ousfane 2 (Mechta et Tein) et Henchir Bou Takrematen (région de Bir Chouada) ; Seriana Pasteur 2(région de Batna) ; Henchir el Atech et Henchir Tarlist(région d'Aïn Azel) ; Et Toual (région de Biskra) ; Djemila, groupe épiscopal,églises 1 et 2 ; église des quartiers Ouest ; église Est.

19 Tous se trouvent en Numidie : reliquaire à Dalaa (région de Kenchela), caisson en l'honneur d'un martyr à Aïn Abid, inscription des martyrs de Milev à Rouffach (région de Constantine).

20 D'après Augustin, il existait au moins sept églises à Hippone. À l'intérieur de la ville, la basilique de la Paix dans le secretarium de laquelle se tint le concile de 393, qui devait être la cathédrale ; la memoria d'Étienne (mais est-ce un édifice ?) qui était liée d'une manière ou d'une autre aux deux lieux de cultes suivants ; l'ecclesia ancienne et l'ecclesia nouvelle, séparées par une maison qu'Augustin souhaitait acquérir (la première correspond-elle à la basilique de la Paix ?) ; la cathédrale donatiste qui se distinguait par des célébrations bruyantes à la saint Léonce. Hors des murs de la ville se trouvaient la basilique de Leontius dans laquelle avaient lieu, le 4 mai, jour anniversaire de l'évêque fondateur, des banquets licencieux condamnés par Augustin - vainement - en 395, la memoria de Theogenes, sans doute l'évêque de 256 ; celle des vingt martyrs et celle des huit martyrs achevée ou reconstruite sous l'épiscopat d'Augustin avant janvier 426. Cependant, les textes restent souvent épars, vagues et ambigus, comme le rappelle MARROU H.-I., 1960, Basilique chrétienne d'Hippone, p. 146, note 172, qui renvoie sur ce problème à PERLER O., L'église d'Hippone, 1955, p. 299-343 et ID., Memoria des Vingt Martyrs, 1956, p. 435-446. 


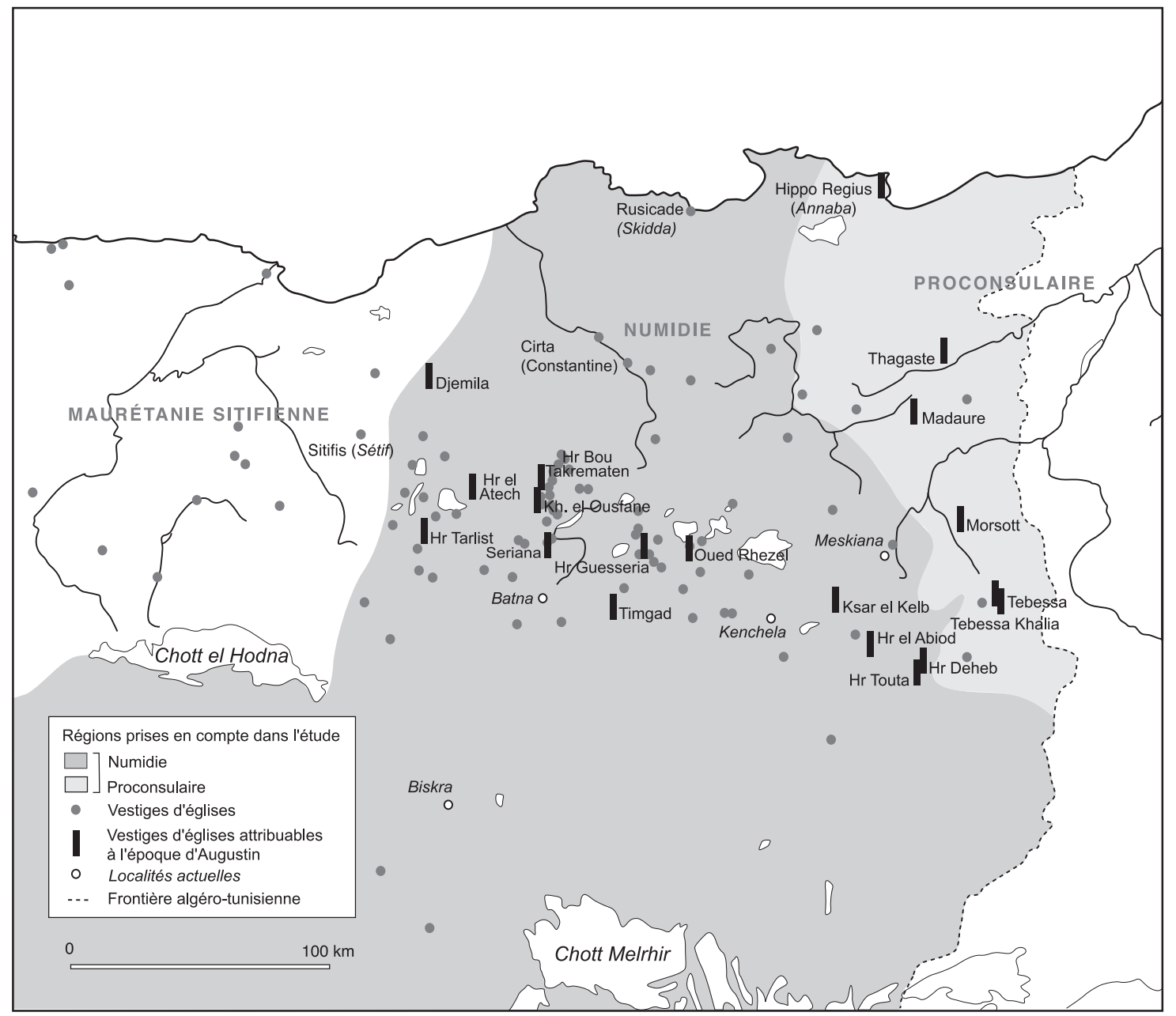

Fig. 1. Localisation des édifices chrétiens de Numidie pouvant remonter à l'époque d'Augustin (dessin A. Michel d'après Gui I., Duval N., CAILlet J.-P., 1992, Basiliques de l'Algérie, 1. Texte, face p. 366). 


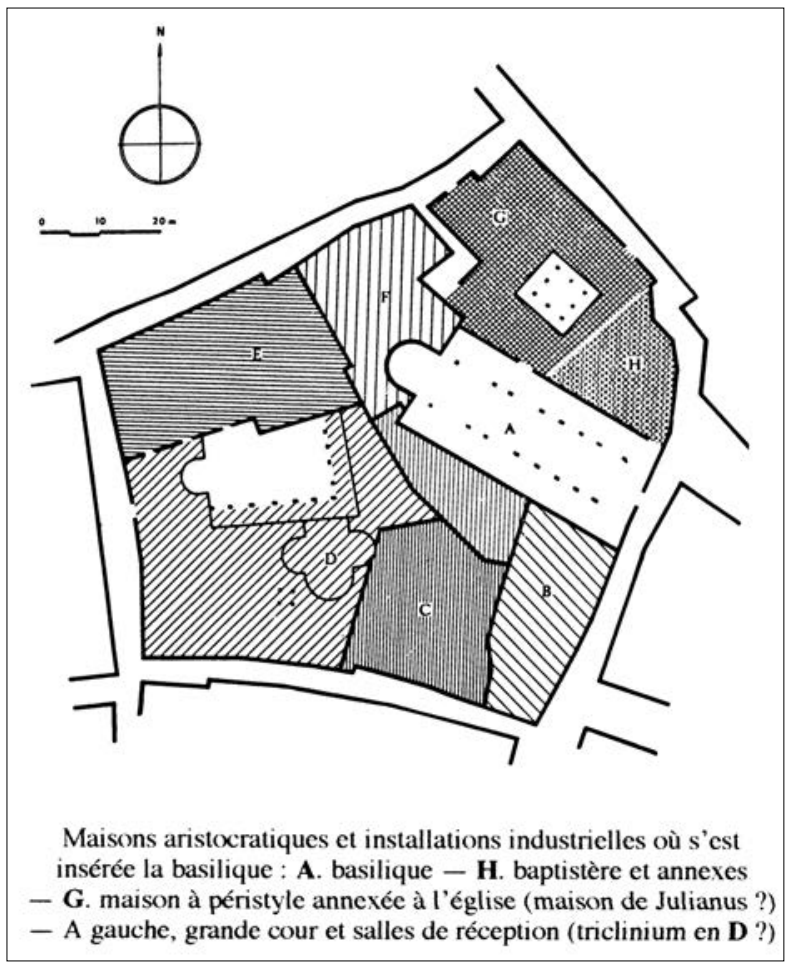

Fig. 2. Hippone, schéma du quartier chrétien d'après Février (GuI I., DuvaL N., CAILlet J.-P., Basiliques de l'Algérie, 2, Illustrations, 1992, pl. 123,1).

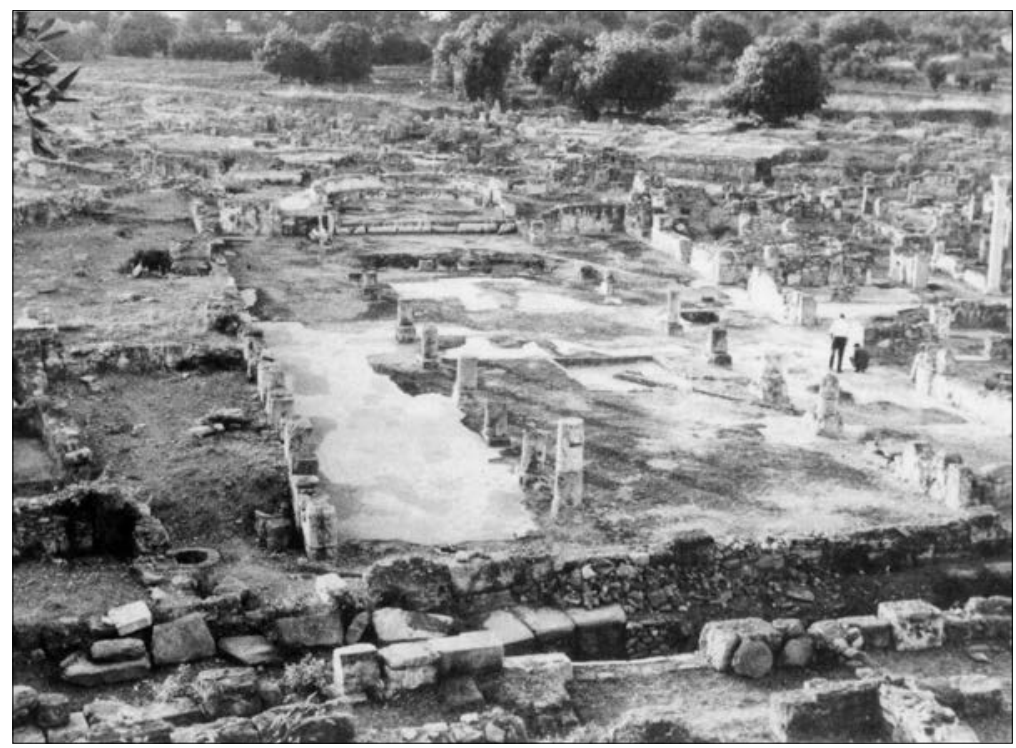

Fig. 3. Hippone, la basilique en 1964

(Gui I., Duval N., CaIllet J.-P., Basiliques de l'Algérie, 2, Illustrations, 1992, pl. 123,3). 
seul édifice a été mis au jour. E. Marec, le fouilleur, identifiait cet ensemble chrétien à l'église d'Augustin ${ }^{21}$ (fig. 2), mais l'interprétation ne peut être prouvée, même s'il est certain que l'édifice existait à l'époque d'Augustin 22. L'église, du fait de sa longue utilisation, reste décevante pour l'archéologue : l'architecture, mal conservée, ne présente rien de spécifique et les aménagements liturgiques ont disparu (fig. 3) ; seules subsistent les nombreuses sépultures attribuées à l'époque vandale ${ }^{23}$. À Madaure, où Augustin fut élève, on a conservé trois édifices voués au culte chrétien, dont deux seulement peuvent remonter à son époque. L'un d'eux fut aménagé dans les petits thermes de la ville probablement avant l'époque vandale (fig. $4, \mathrm{n}^{\circ} 3$ ). Le troisième bâtiment chrétien remonterait à la seconde moitié du ve siècle. Aucun vestige chrétien n'est apparemment connu à Thagaste.

Cependant les vestiges existants, malgré leur caractère disparate qui interdit toute synthèse précise, permettent de saisir le cadre monumental du culte chrétien et différents aspects de la piété populaire dont les sources écrites ne rendent pas toujours compte avec autant de précision.

La majeure partie des églises sont, comme dans tout le monde chrétien de cette époque, des basiliques. Contrairement à ce que l'on pourrait attendre d'une Église africaine bien spécifique, ces basiliques ne présentent guère de particularités architecturales par rapport aux autres édifices d'Occident ${ }^{24}$. Proches dans leur organisation de la basilique latine, elles sont généralement dépourvues d'atria : on y accède plutôt par un simple vestibule (Henchir Deheb, Henchir el Atech) (fig. 5). Il s'agit surtout d'édifices à trois nefs, séparées soit par des colonnes, soit par des piliers dont peu de vestiges subsistent généralement. La seule originalité marquante apparaît dans la région de Tébessa (Tébessa, Henchir Deheb, Morsott 1), avec l'emploi de supports doubles (deux colonnes adossées ou

21 MAREC E., Hippone, 1958.

22 Dans la lettre 29,11 qu'il envoie en 395 à son ami Alypius, évêque de Thagaste, Augustin signale qu'il entend les célébrations de banquets dans la cathédrale donatiste voisine qui le gênent lors de la célébration liturgique ; les deux édifices ne sont apparemment séparés que par une maison. En fait, l'église à cinq nefs identifiée comme telle à l'origine par Marec ne peut être considérée comme un édifice religieux. MAREC E., Hippone, 1958, p. 219-220 revient d'ailleurs lui-même sur sa première interprétation en renonçant à considérer le bâtiment comme l'édifice donatiste, en se fondant sur une traduction différente de la lettre (Augustin "entend dire que" au lieu "d'entend" les célébrations qui ont lieu dans la cathédrale donatiste). La lettre 29,11 ne peut donc servir d'argument pour identifier l'église dégagée à la cathédrale d'Augustin. P.-A. FÉVRIER, Sources épigraphiques, 1972, p. 148-150, fait en outre remarquer qu'il n'existait pas de lien direct entre la maison à péristyle sud-ouest et la basilique - aucune trace de porte n'est visible dans des maçonneries bien conservées - ceci d'autant plus que les deux bâtiments étaient séparés par une dénivellation d'1,00 m. La salle tréflée au sud-ouest de la basilique ne pourrait donc être l'édifice qui a abrité les reliques du protomartyr Étienne construite par le diacre Eraclius comme le supposait E. Marec ; il s'agirait en fait d'un simple triclinium de villa comme il en existe de nombreux dans l'Antiquité Tardive. Les réticences face à l'interprétation proposée par E. Marec apparaissent générales, aussi bien de la part de LASSUS J. dans la préface du livre de MAREC E., 1958, Hippone, p. 8, que de MARROU H.-I., Basilique chrétienne d'Hippone, 1960, p. 146-148, ou de DUVAL N., Compte rendu du livre de MAREC E., 1958, Hippone, Karthago, 9, 1958 (1959), p. 275-276, qui hésitent ou se refusent à considérer l'édifice comme la cathédrale d'Augustin.

23 Marrou H.-I., Basilique chrétienne d'Hippone, 1960, p. 135-143.

24 Duval N., Basilique chrétienne africaine, 1991, p. 1371-1377. 


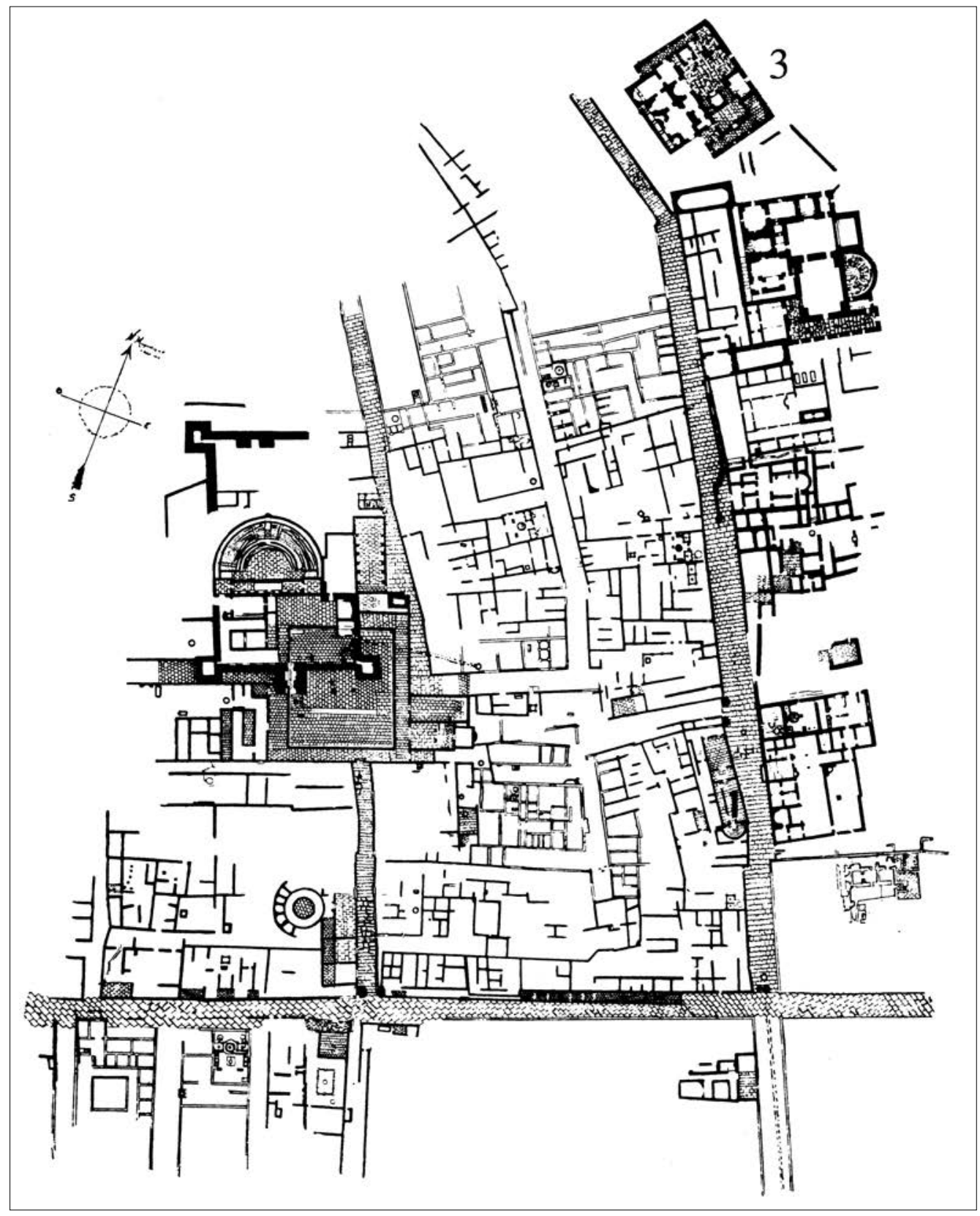

Fig. 4. Madaure, plan du centre antique de la ville d'après Christofle

(Gui I., Duval N., CAILlet J.-P., Basiliques de l'Algérie, 2, Illustrations, 1992, pl. 164). 


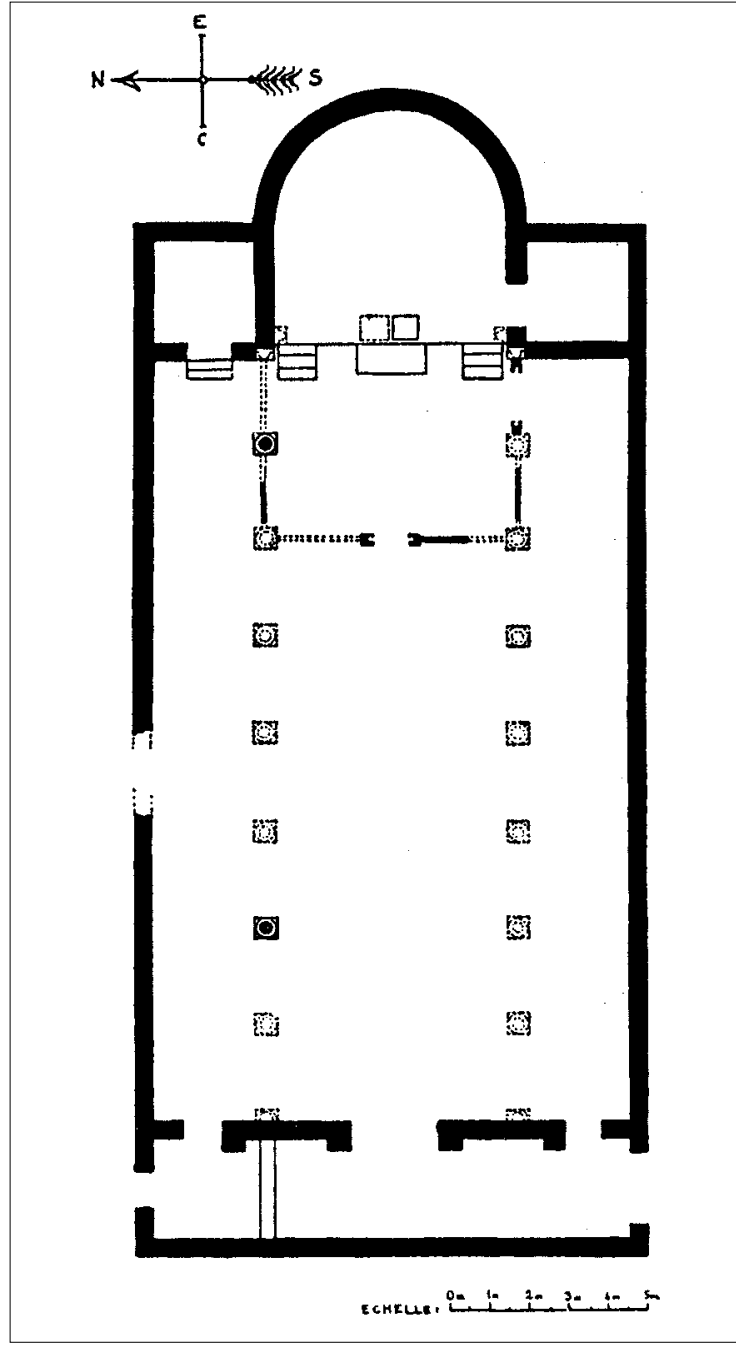

Fig. 5. Henchir el Atech, plan de l'église d'après Simon (Gui I., Duval N., CAillet J.-P., 1992,

Basiliques de l'Algérie, 2, Illustrations, pl. 76,6). une colonne adossée à un pilier) pour séparer les nefs ${ }^{25}$. Le dispositif réapparaît à Timgad (Timgad 7 et dans d'autres églises de Timgad postérieures à la période prise en compte ici) et ponctuellement à Djemila (église Sud du groupe épiscopal). Les nefs se terminent par une abside qui est soit saillante (Henchir el Atech, Henchir Tarlist, Henchir Guesseria, Timgad 7, Ksar el Kelb, Henchir Deheb), soit inscrite entre une (Kherbet el Ousfane) ou deux sacristies (Tébessa, Timgad 1).

Six des édifices envisagés possèdent un baptistère, mais sa présence, surtout s'il est isolé sans autres dépendances autour de l'édifice, ne suffit pas à identifier ces églises comme appartenant à des groupes épiscopaux, notamment lorsqu'on ne possède aucune indication de chronologie relative, puisqu'aux époques tardives la prérogative de l'évêque en matière de baptême n'était plus systématique ${ }^{26}$. L'emplacement de ces six baptistères n'obéit à aucune règle fixe. La cuve peut être placée dans une pièce située derrière l'abside (Morsott 1 ou Hr. Deheb) ou en façade de l'église (basilique Nord du groupe épiscopal de Djemila, Henchir Bou Takrematen 2). À Tébessa, le baptistère a été aménagé dans une pièce à l'angle sud-ouest de l'atrium et à Hippone, son implantation au nord-est de l'église s'explique par le remploi de

25 Christern J., Tebessa, 1976, p. 152-157 sur le "groupe de Tebessa". Aux édifices mentionnés, il faut ajouter les églises 1 et 3 de Thélepte, aujourd'hui en territoire tunisien.

26 Cf. Duval N., LASsus J., FÉVRIER P.-A., Groupes épiscopaux, 1972, . 215-244 ; DuvAl N., FÉVRIER P.-A., L'évêque et la cathédrale, vol. I, 1989, p. 345-403. 
structures plus anciennes réaménagées pour la circonstance. On ne possède pas, pour ces édifices, d'éléments de chronologie relative, et encore moins de chronologie absolue ; tout au plus le baptistère de Djemila est-il attribué d'après le style des pavements aux IVe_ ve siècles.

Les conclusions que l'on peut tirer de l'étude architecturale des bâtiments retenus pourront sembler décevantes à l'historien. De fait, c'est surtout l'organisation interne des aménagements liés au culte qui témoigne de l'originalité de l'église d'Afrique et de certains aspects qui relèvent de la piété populaire.

L'abside, où siégeaient les membres du clergé, est surélevée de 0,45 m à 1,00 m dans 12 des 20 églises envisagées (Tébessa, Morsott 1, Henchir Deheb, Henchir Guesseria, Timgad 1, Kherbet el Ousfane 1, Henchir Bou Takrematen 2, Oued Rezel 4, Henchir Tarlist 1). La surélévation atteint 1,20 m à Henchir el Atech, 1,46 m à Ksar el Kelb, 1,80 m à Djemila dans l'église du quartier Ouest. On y accédait le plus souvent, en tout cas en Numidie centrale, par deux escaliers, sauf dans l'église 4 d'Oued Rezel et dans l'église 1 d'Henchir Tarlist, où il n'y en avait qu'un ${ }^{27}$.

Cette surélévation de l'abside n'est apparemment liée à aucune nécessité architecturale, sauf à Ksar el Kelb, où des tombes et des sarcophages étaient enfouis sous le sol de l'abside (cf. infra). Dans certains cas, elle s'explique par la présence d'une crypte sous-jacente. L'aménagement reste relativement rare puisqu'I. Gui n'en a dénombré que 25 pour toute l'Algérie (dont dix d'identification douteuse) ${ }^{28}$, mais un quart sont concentrées dans la province ecclésiastique de Numidie, tout particulièrement à Djemila, où les quatre églises connues jusqu'à présent possédaient une crypte. Une cinquième crypte apparaît dans l'église 1 de Timgad, implantée dans la nécropole qui borde la voie menant à la porte de Lambèse. Ce sont là les seules cryptes bien attestées, car dans l'église aménagée dans les petits thermes de Madaure, seule une série de trous de poutres visibles $90 \mathrm{~cm}$ au-dessus du niveau du seuil du presbyterium installé dans une piscine thermale laisse supposer l'existence d'une crypte. À Henchir Guesseria, il s'agit en fait plutôt, compte tenu des dimensions (1,50 x 1,20 x 1,00 m de haut) et de l'emplacement de l'aménagement, d'une fosse d'autel (voir infra).

Les cinq cryptes de Numidie bien attestées étaient implantées soit sous l'abside, soit sous le chœur et l'abside des églises. Le plan de la crypte reprend en général celui de l'abside de l'édifice érigé au-dessus. À Djemila, le chevet de l'église est restitué par rapport à celui de la crypte pour les deux basiliques du groupe épiscopal et pour l'église des quartiers Est. L'élévation de la crypte y reste d'ailleurs mal connue puisque la partie haute des murs a disparu. Seule la crypte de l'église des quartiers Ouest était mieux conservée peut-être parce qu'elle correspond à une ancienne memoria ensuite intégrée dans l'église ${ }^{29}$.

27 Encore cet état résulte-t-il apparemment d'un remaniement dans cette dernière église.

28 Duval N. et FÉvrIER P.-A., Basilique cimétériale de 1'Est, 1991, p. 138.

29 Allais Y., Basilique cimétériale, 1962-1965, p. 200 ; contra Gui I., Duval N., CAILleT J.-P., Basiliques de l'Algérie, 1992, p. 101 qui discutent l'hypothèse. 


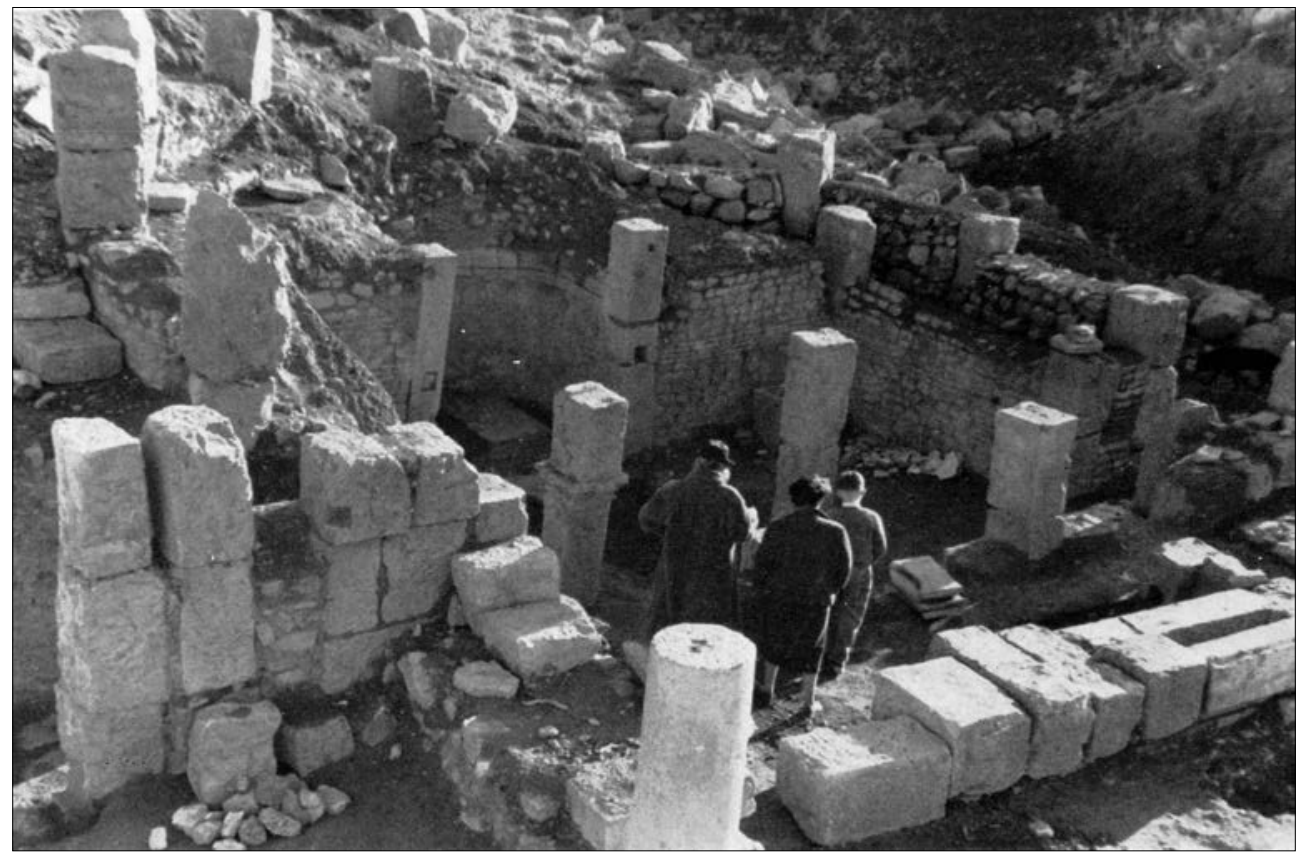

Fig. 6. Djemila (Cuicul), église Ouest. La crypte vue depuis la nef (AllaIS Y., Basilique cimétériale, fig. 6, 1962-1965, p. 197).

Il s'agit d'une confession rectangulaire $(6,30 \times 4,60 \mathrm{~m})$ dont le sol se trouvait à $0,90 \mathrm{~m}$ en contrebas de celui de la nef, placée sous l'abside de l'église, qui était surélevée de 1,80 m (soit une hauteur totale de 2,70 m pour la crypte). Au Sud/Sud-Ouest, la salle se terminait par une petite abside voûtée en cul-de-four. Elle était probablement couverte par un plafond maçonné que supportaient quatre piliers en pierre de taille hauts de 2,40 m (fig. 6). Toujours à Djemila, les cryptes du groupe épiscopal comportaient deux salles semi-circulaires reliées par un couloir transversal qui courait sous le chevet des deux édifices. La crypte de l'église Nord faisait face à une profonde exèdre en hémicycle, tandis que trois niches semicirculaires s'ouvraient en face de la crypte méridionale (fig. 7 et 8). Une organisation semblable paraît avoir été adoptée dans l'église du quartier Est, érigée dans une zone cimétériale, où le sol de la crypte, en partie remblayée, se trouvait 2,10 m en contrebas du sol des nefs (fig. 9). Dans l'église 1 de Timgad, la crypte se présentait comme une salle haute de 2,20 m, subdivisée par deux files de piliers, qui s'étendait sous l'abside et ouvrait sur deux pièces aménagées sous la sacristie septentrionale (fig. 25). L'accès à ces cryptes se faisait, lorsqu'il est connu, par l'extrémité d'un des collatéraux de l'église. On le voit, ces cryptes restent un aménagement assez rare et leur présence ne saurait expliquer la surélévation de l'abside dans les églises de Numidie. 


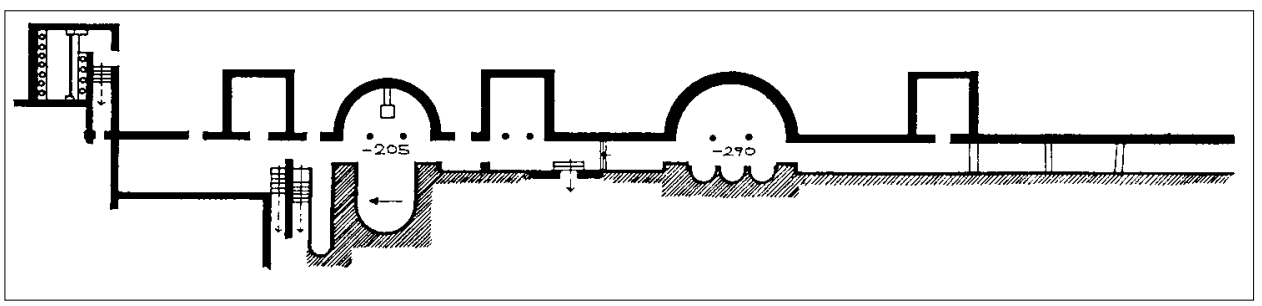

Fig. 7. Djemila (Cuicul), plan des cryptes du groupe épiscopal d'après Christern (Gui I., Duval N., CAILlet J.-P., Basiliques de l'Algérie, 2, Illustrations, 1992, pl. 77,1).

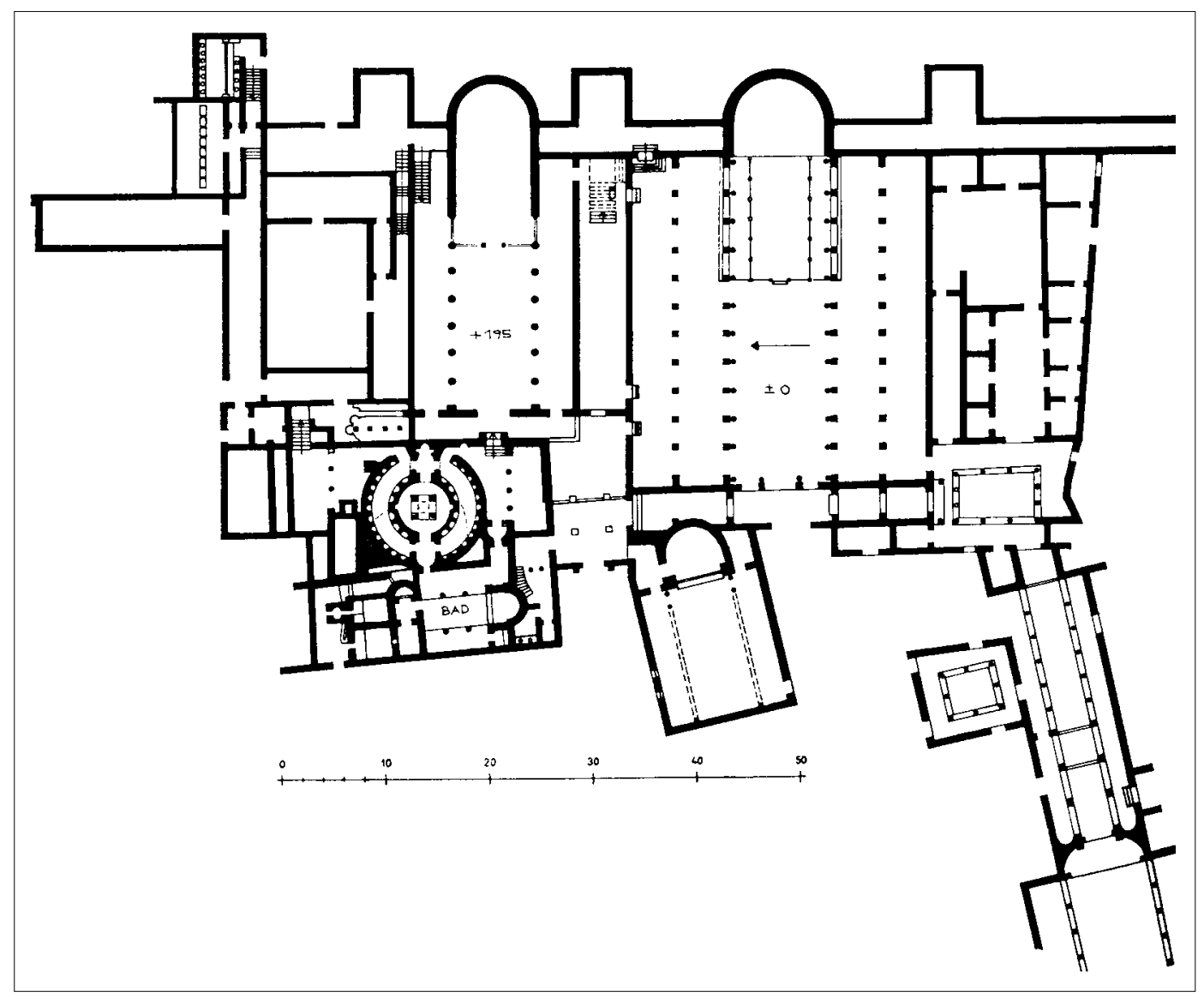

Fig. 8. Djemila (Cuicul), plan restitué du groupe épiscopal d'après Christern (Gui I., Duval N., CAILlEt J.-P., Basiliques de l'Algérie, 2, Illustrations, 1992, pl. 77,1). 


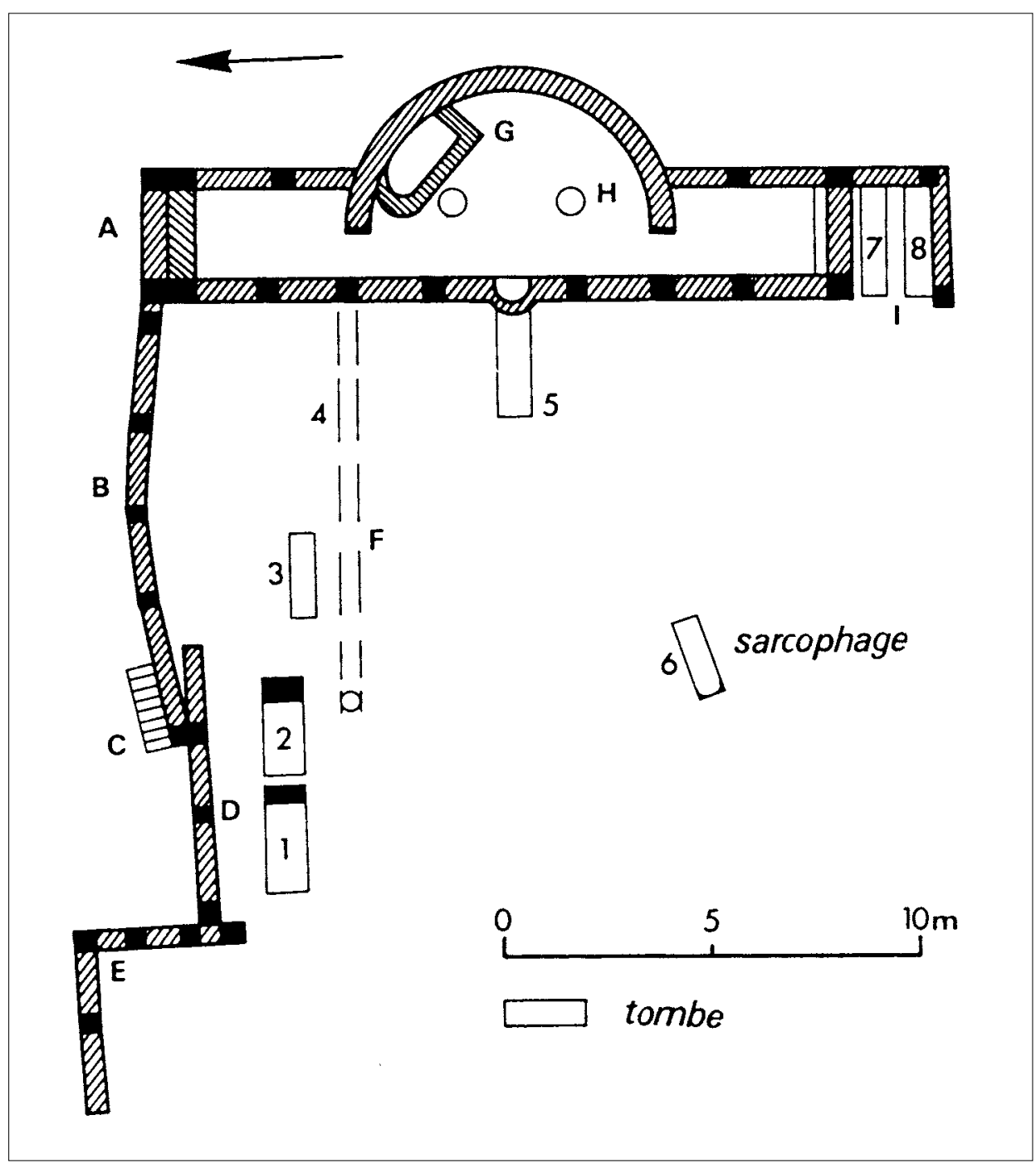

Fig. 9. Djemila (Cuicul), plan de la basilique cimétériale Est d'après Bailly (Duval N. et FÉvRIER P.-A., 1991, Basilique cimétériale de l'Est, fig. 2). 
L'abside dominait ainsi largement le chœur qui était normalement délimité par des clôtures composées de plaques encastrées dans des poteaux et maintenues dans un rail de pierre, parfois partiellement conservé dans le sol de l'édifice. Les traces laissées par le chancel ne permettent pas toujours de restituer avec exactitude son extension ; néanmoins, dans la plupart des cas, il était assez profond (11,00 m dans les deux églises du groupe épiscopal de Djemila), englobant souvent les deux à trois dernières travées de la nef centrale (Morsott 1 , Henchir el Atech, Henchir Tarlist 1, Henchir Bou Takrematen 2, Djemila Ouest, Ksar el Kelb). Il s'étendait plus rarement à une partie des collatéraux, comme à Ksar el-Kelb, où l'aménagement doit être mis en relation avec la memoria de Marculus aménagée à l'extrémité du collatéral sud (fig. 17). À Tébessa, le chœur, profond de trois travées, se prolongeait peut-être à l'origine par un couloir qui menait à un contre-chœur dont le dessin des panneaux de mosaïque de la nef conserve la trace $^{30}$ (fig. 11). Une organisation voisine du chœur apparaît également dans l'église aménagée dans les petits thermes de Madaure (fig. 10).

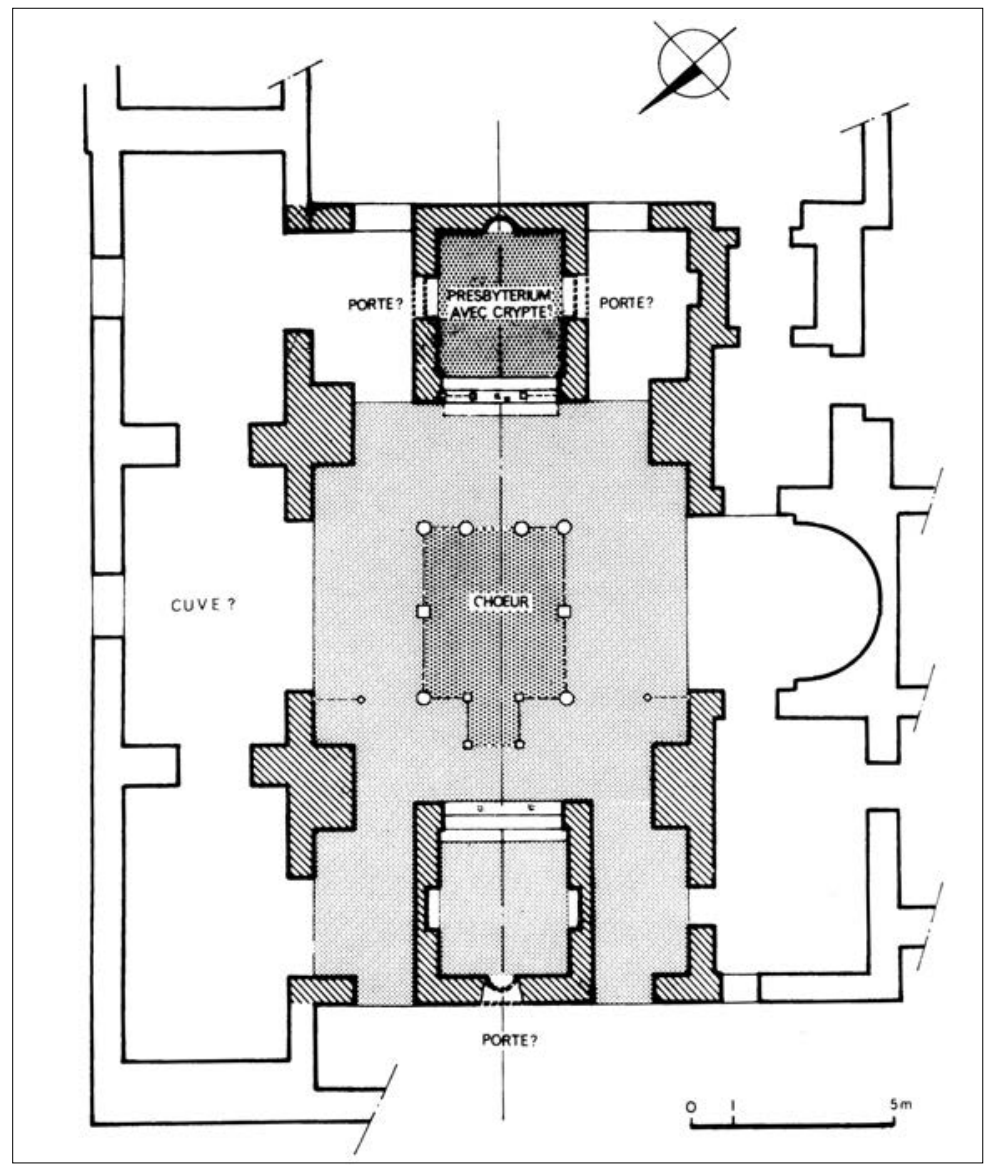

30 Duval N., Églises à deux absides, 2, 1973, p. 36-38.
Fig. 10. Madaure, installations chrétiennes dans les petits thermes d'après Duval (GUI I., Duval N., CAILlet J.-P., Basiliques de l'Algérie, 2, Illustrations, 1992, pl. 117,4). 


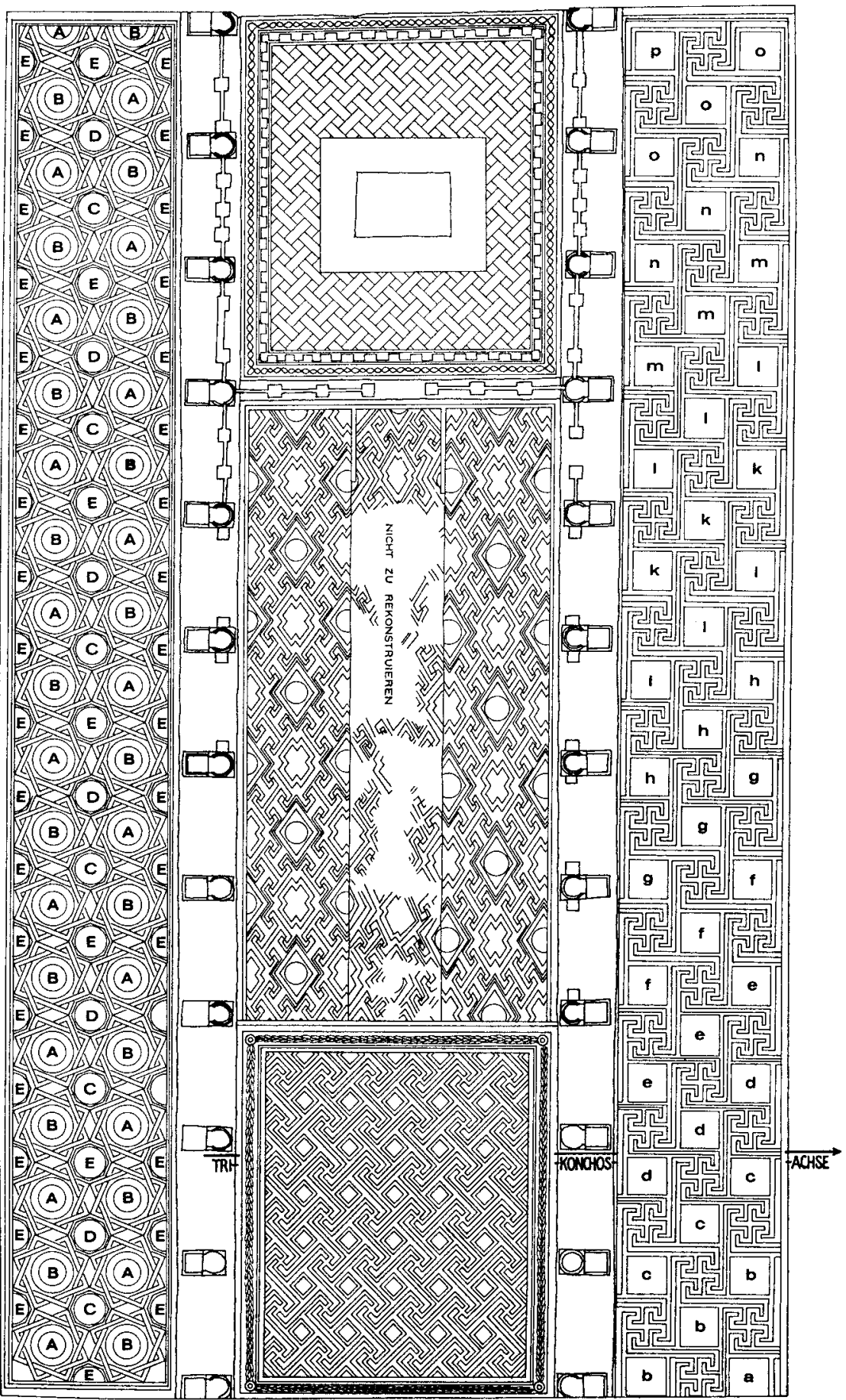

Fig. 11. Tébessa, restitution graphique des mosaïques de la nef de la basilique (Christern J., Tebessa, fig. 17, 1976, p. 68). 
L'autel est en principe placé très en avant dans la nef en Afrique, notamment aux époques anciennes, en tout cas avant l'époque byzantine. Curieusement, parmi les édifices considérés, les rares vestiges de l'autel qui ont été préservés (à cinq reprises seulement - six si l'on tient compte de Madaure 3) semblent indiquer - à l'exception de l'église aménagée dans les petits thermes de Madaure - qu'il se trouvait bien dans la nef, mais relativement

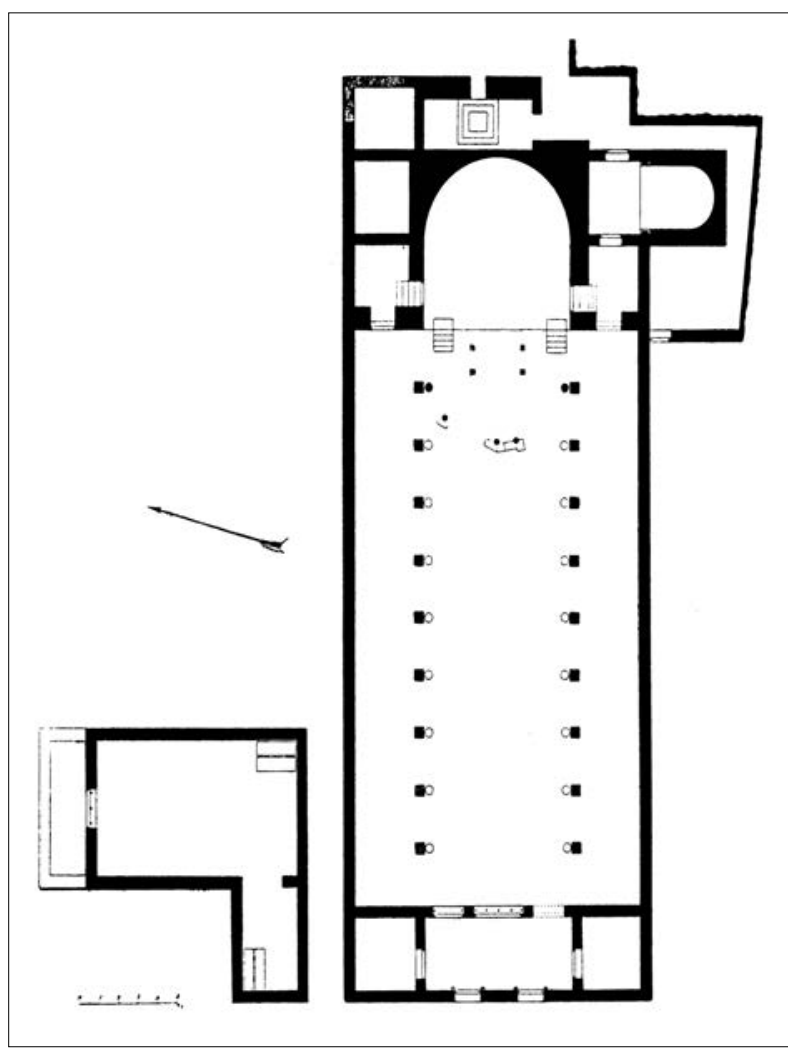

Fig. 12. Morsott, plan de la grande basilique d'après Gsell (Gui I., Duval N., CaIllet J.-P.,

Basiliques de l'Algérie, 2, Illustrations, 1992, pl. 159, 3). proche de l'abside. Dans l'église 1 de Morsott, il n'en reste que quatre trous délimitant une surface de 2,79 x 1,28 m - qui peuvent correspondre à un ciborium - située $5 \mathrm{~cm}$ devant l'abside (fig. 12). À Henchir el Atech, le fouilleur M. Simon considère que les deux dalles conservées sur la corde de l'abside surélevée d'1,20 m permettent de restituer l'emplacement de l'autel ${ }^{31}$, mais selon I. Gui, il faut plutôt le restituer plus en avant, juste au pied de la corde de l'abside, audessus d'un sarcophage ${ }^{32}$. On retrouverait la même situation à Ksar el Kelb, où P. Courcelle ${ }^{33}$ restitue un ciborium "dans la région de l'autel" qui serait placé, d'après le sarcophage sous-jacent, juste devant l'abside, dans la dernière travée de la nef. Il est certes vraisemblable de considérer qu'il s'agit là des traces laissées par l'état tardif de l'autel, qui serait le seul conservé, mais les vestiges en sont souvent bien ténus pour aboutir à une conclusion ferme 34

31 SimON M., Henchir el Ateuch, 1934, p. 160.

32 Gui I., Duval N., CAILlet J.-P., Basiliques de l'Algérie, 1992, p. 118.

33 CourCElle P., Ksar el-Kelb, 1936, p. 174.

34 FÉVRIER, P.-A., Fouilles de Sétif, 1965, p. 53-54 s'en tenait à la même prudence quant à ces édifices : "Je relève de ces exemples que la présence d'un autel n'est pas toujours assurée ; on l'a parfois supposée, à juste titre parfois, mais souvent sans preuve contraignante." 
Ils ne permettent guère, même, de restituer la typologie de la table. Tout au plus peuton considérer qu'il s'agissait d'autels-coffres dans l'église 2 de Seriana (Pasteur) et dans l'église 2 de Kherbet el Ousfane. Dans la première subsistaient, à la corde de l'abside, les traces d'un coffre cimenté de $0,45 \mathrm{~m}$ de côté, surmonté d'une dalle de $1,30 \times 0,70 \mathrm{~m}$ qui est considérée comme la base d'un autel-coffre ${ }^{35}$. Dans la seconde, S. Gsell signale trois fragments de piliers de pierre avec des bandes en saillie décorées, qu'il interprète comme des éléments d'un autel-coffre ${ }^{36}$.

Ce sont là de bien maigres indications quant à l'organisation liturgique des édifices considérés. On ne peut que constater, que, comme dans les autres régions d'Afrique, le clergé siégeait dans l'abside, à distance de l'autel qu'il dominait largement, ainsi que la foule des fidèles. Toute autre généralisation s'avèrerait hâtive du fait du petit nombre d'édifices sur lesquels ces remarques se fondent, d'autant plus que l'organisation interne peut varier en fonction de l'histoire spécifique du bâtiment.

Cependant, l'un des aspects les plus marquants du culte dont les traces subsistent dans les églises reste celui des saints et martyrs. Les vestiges archéologiques révèlent l'ampleur de ce phénomène dont les sources écrites laissent seulement entrevoir l'existence. En effet, les traités de Tertullien et la correspondance de Cyprien de Carthage ne signalent que rapidement la célébration annuelle de la liturgie eucharistique pour l'anniversaire du martyre dès le IIII siècle, sans apporter de précisions ${ }^{37}$. En 401 , la décision prise au concile de Carthage de détruire les fausses memoriae des martyrs, c'est-à-dire celles dont l'autel ne contenait ni la tombe, ni les reliques, montre qu'au début du ve siècle, la nécessité de consacrer l'autel par des restes matériels s'imposait déjà ${ }^{38}$.

Ces restes matériels associés à l'autel ont évolué nettement entre le IVe siècle et l'époque byzantine. Aux époques les plus anciennes, le culte des martyrs était étroitement lié au culte funéraire privé, ce dont témoignent dans les nécropoles divers aménagements autour des tombeaux des martyrs ou sur le lieu de leur souffrance, que P.-A. Février ${ }^{39}$ et Y. Duval ${ }^{40}$ ont pu mettre en évidence. Dès le IVe siècle se développent autour de la sépulture des martyrs des enclos (area cincta), des mausolées, parfois associés à une basilique, des églises construites autour du corps du martyr (basiliques ad corpus), où l'autel est alors associé à la tombe du martyr. Ces mausolées et basiliques ad corpus attestés sans ambiguïté par l'archéologie et l'épigraphie restent peu nombreux. Exceptée la memoria de Tébessa (cf. infra), ils se limitent à quelques sites dont aucun n'appartient à la Numidie : Bénian (tombeau et basilique de Robba) et Tipasa (basilique Sainte-Salsa et basilique d'Alexandre) en Maurétanie césarienne, Carthage (Bir Ftouah, Damous el Karita, Basilica Maiorum) en Proconsulaire.

35 Gui I., Duval N., Caillet J.-P., Basiliques de l'Algérie, 1992, p. 153, d'après Gsell St., 1901, Monuments, II, p. 255.

36 GSELl St., Monuments, II, 1901, p. 247.

37 Tertullien, De Corona, 6 ; De exhortatione castitatis, 11 ; CYPRIEN De CARThage, Ep. 39, III, 1 ; Ep. 12 , II, 1. Cf. aussi Duval Y., Loca sanctorum, II, 1982, p. 456

38 Duval Y., Loca sanctorum, II, 1982, p. 457.

39 FÉVRIER P.-A., Inhumation privilégiée, 1986, p. 13-23.

40 Duval Y., Loca sanctorum, 1982. 


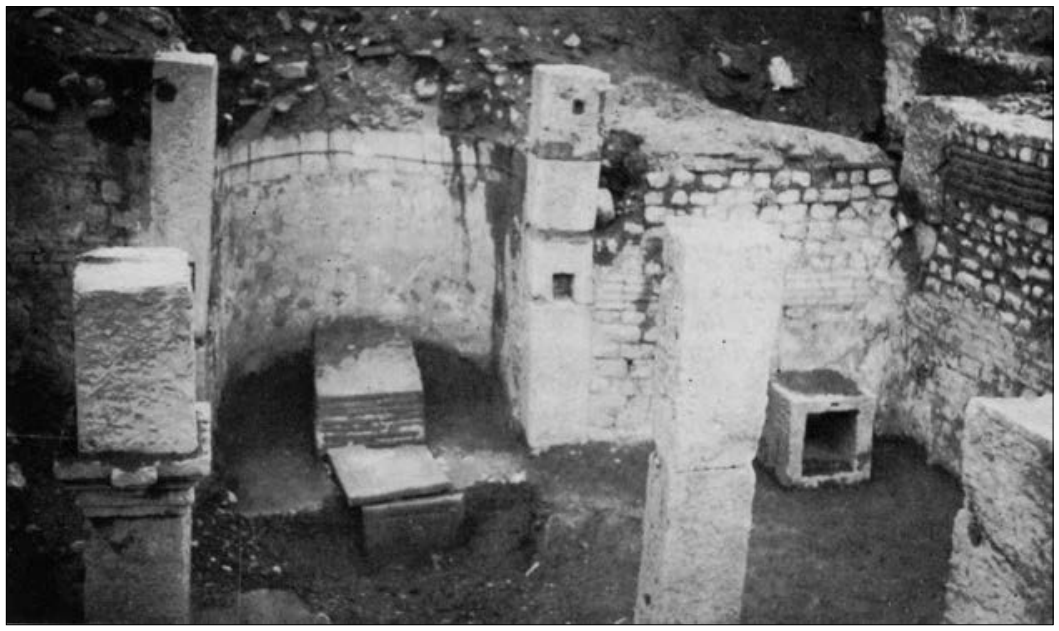

Fig. 13 (à gauche). Djemila (Cuicul), église Ouest. La crypte après restauration (AllaIS Y., Basilique cimétériale, fig. 8, 19621965, p. 199).

Cependant, lorsque dans une basilique l'autel est directement placé au-dessus d'une tombe, il est évident qu'elle jouit d'une vénération spécifique. Malgré l'anonymat du défunt, on peut alors admettre qu'il s'agit d'une basilique ad corpus d'un des nombreux martyrs locaux qui existaient en Afrique, $a$ fortiori si l'édifice se trouve dans une nécropole ${ }^{41}$.

C'est probablement le cas, en Numidie, de l'église du quartier Ouest de Djemila. L'édifice fut érigé sur une crypte (cf. supra) dont l'abside contenait une tombe qui était associée à des fragments de mensa (fig. 13 et 14$)^{42}$. On pouvait contempler l'aménagement depuis le chœur de l'église par trois fenestellae ouvertes dans le mur de la crypte (fig. 15) qui s'élevait $1,80 \mathrm{~m}$ au-dessus du niveau des nefs. S'il est tentant de considérer cette sépulture comme celle d'un martyr du fait de son emplacement sous l'abside de l'église, on peut en revanche s'interroger sur la tombe découverte dans le chœur à la hauteur de la dernière travée de la

Fig. 14 (à droite). Djemila (Cuicul), église Ouest. Tombe conservée dans l'abside de la crypte avant restauration (AllaIs Y., Basilique cimétériale, fig. 7, 1962-1965, p. 197).

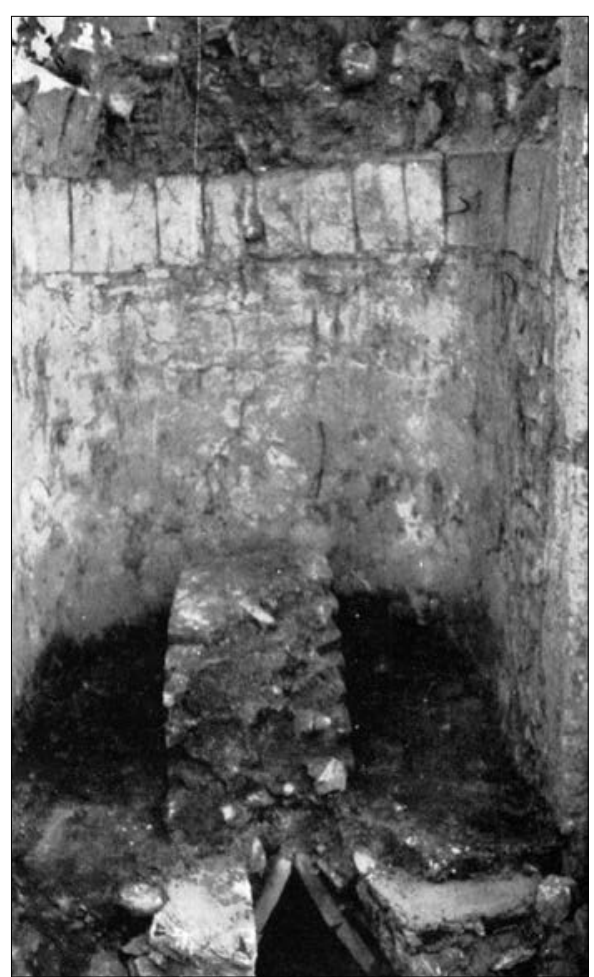

41 Duval Y., Loca sanctorum, II, 1982, p. 463 et 516.

42 ALLAIS Y., Basilique cimétériale, 1962-1965,p. 198, signale la découverte, lors de la fouille, de fragments de marbre associés à la tombe. 


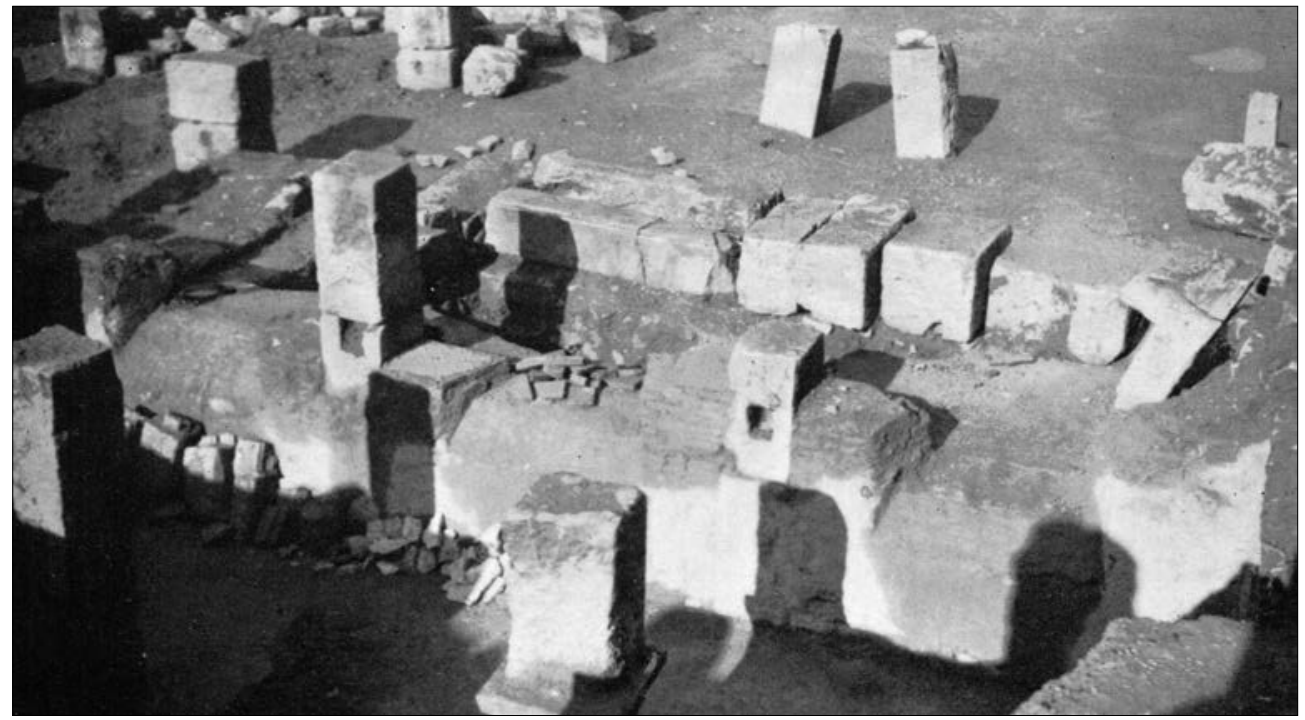

Fig. 15. Djemila (Cuicul), église Ouest. Fenestellae aménagées dans le mur séparant la crypte du chœur de l'église, vues depuis l'abside (Allais Y., Basilique cimétériale, fig. 5, 1962-1965, p. 195).

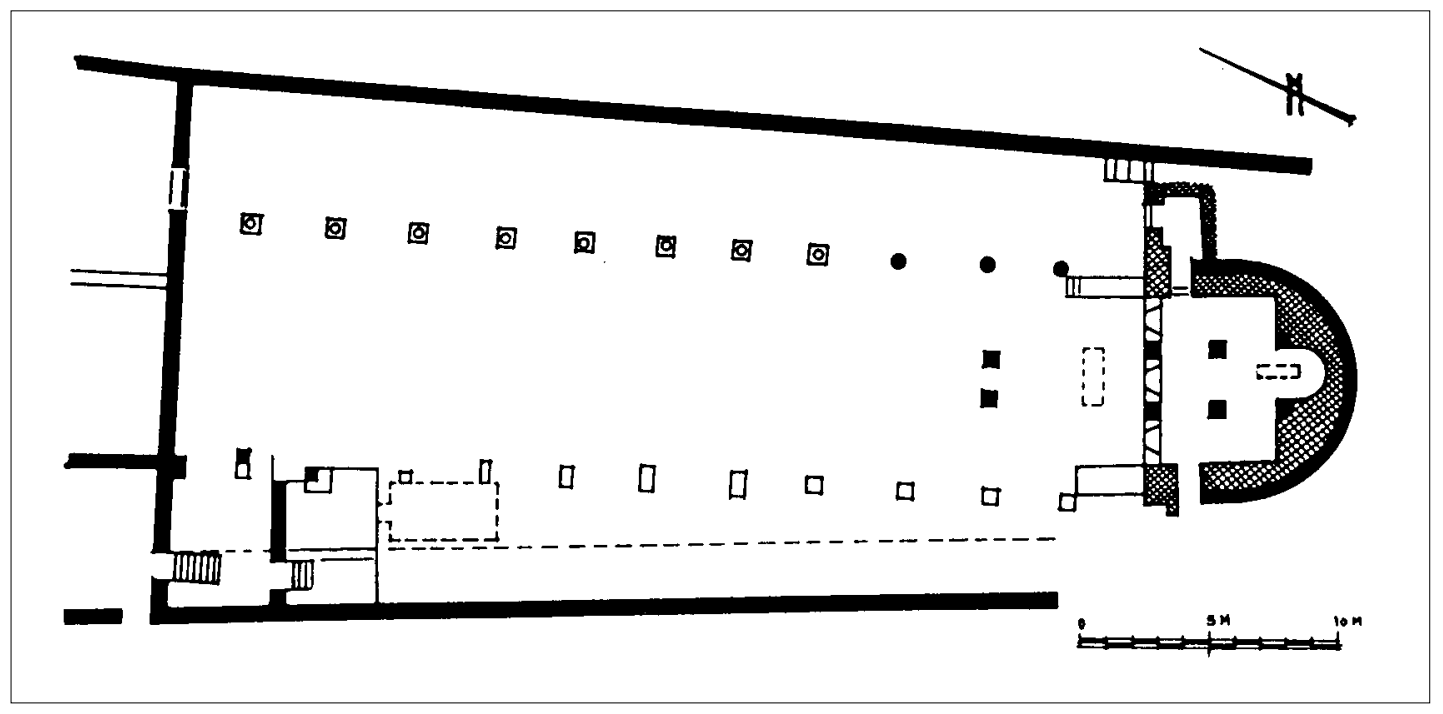

Fig. 16. Djemila (Cuicul), plan de l'église Ouest d'après Allais

(Gui I., Duval N., CAILlet J.-P., Basiliques de l'Algérie, 2, Illustrations, 1992, pl. 73, 1). 
nef, perpendiculairement à l'axe de l'église (fig. 16). Il s'agit d'une fosse rectangulaire $(1,82$ x $0,60 \times 0,90 \mathrm{~m}$ ) maçonnée en briques recouvertes de chaux qui contenait encore, au moment de la fouille, le squelette d'un défunt qu'Y. Allais considère comme celui d'un saint protecteur des enfants en raison des sépultures d'enfants trouvées autour et au-dessus du caveau ${ }^{43}$. L'interprétation dépend en grande partie de la chronologie que l'on peut attribuer à ces aménagements. Y. Allais restitue l'emplacement de l'autel au-dessus de ce caveau qu'elle semble considérer comme une installation contemporaine de l'aménagement de l'église au-dessus d'une memoria plus ancienne ${ }^{44}$. Cependant, on se demande alors quelle était la nécessité des fenestellae dans une memoria indépendante. Ces ouvertures devraient logiquement remonter à l'aménagement de l'église afin de permettre d'apercevoir la tombe de la crypte depuis le chœur, mais le caveau découvert dans le chœur gêne l'accès aux fenestellae et l'on peut se demander s'il ne correspond pas en fait à un aménagement encore plus tardif. Quoi qu'il en soit, même si l'on considère que ce tombeau marque l'emplacement de l'autel, faut-il pour autant le considérer comme une seconde tombe sainte comme le propose Y. Allais ? Le phénomène serait étonnant dans une église attribuée à l'époque byzantine où l'on pratique plutôt le dépôt de reliques. Doit-on alors remonter la chronologie de l'église ou interpréter ce caveau comme une simple inhumation ad sanctos?

À Ksar el Kelb et à Henchir el Atech on peut en revanche se trouver en présence de basiliques ad corpus érigées auprès de tombes saintes. À Ksar el Kelbune tombe subsistait devant l'abside dans l'axe de l'église lors des fouilles en 1934 (fig. 17). Enfouie à $40 \mathrm{~cm}$ de profondeur sous le niveau du chœur, il s'agissait d'un sarcophage monolithe inséré dans une cavité creusée dans la roche, juste à ses dimensions. De part et d'autre, se trouvaient deux pierres, qui avaient disparu lors de la reprise des fouilles en 1936. P. Cayrel, le premier fouilleur, pensait qu'elles avaient "été placées là plus tardivement" ${ }^{45}$, tandis que P. Courcelle qui reprit la fouille en 1936, considérait qu'elles pouvaient avoir appartenu à une clôture protégeant l'aménagement, peut-être un ciborium $^{46}$. Faut-il plutôt voir dans ces pierres les restes de l'autel placé au-dessus du sarcophage ? On peut hésiter, compte tenu de leur forme et de leur emplacement par rapport à la tombe, car l'autel ne l'aurait pas recouverte en totalité. À Henchir el Atech, un sarcophage contenant deux corps, ensevelis

43 Allais Y., Basilique cimétériale, 1962-1965, p. 194-196.

44 La chronologie de la crypte et de l'église reste débattue. La fouilleuse, Y. ALLAIS, Basilique cimétériale, 1962-1965, p. 200-205, considère que la crypte est une ancienne memoria du IVe siècle intégrée ensuite à l'église. La date est avancée d'après la maçonnerie de la crypte, qui est très proche de celle de la basilique civile du nouveau forum érigé sous Valentinien et Valens entre 364 et 367. Cette memoria aurait été transformée en crypte pour l'église érigée, d'après la rusticité de la maçonnerie, à l'époque byzantine après la défaite des Vandales, au moment où la cité était appauvrie. L'interprétation n'emporte pas entièrement l'adhésion de DUVAL N. et FÉVRIER P.-A., Basilique cimétériale de l'Est, p. 140, qui pensent à un "aménagement volontaire" - donc contemporain de l'église ? - "puisqu'il en existe [des cryptes] dans les trois autres églises [de Djemila]. ” Gui I., Duval N., CAILlET J.-P., Basiliques de l'Algérie, 1992, p. 73 considèrent que l'inscription de dédicace à la "Paix éternelle" de quatre empereurs, qu'on peut attribuer au début du IV' siècle, gravée sur la pierre remployée pour le couvercle de la tombe placée dans la crypte ne donne qu'un terminus post quem somme toute peu significatif pour dater la tombe de la crypte. Il faudrait, pour trancher, pouvoir procéder à un réexamen soigneux des maçonneries de l'église et de la crypte.

45 CAYREL P., Basilique donatiste, 1934, p. 122

46 Courcelle P., Ksar el Kelb, 1936, p. 174. 


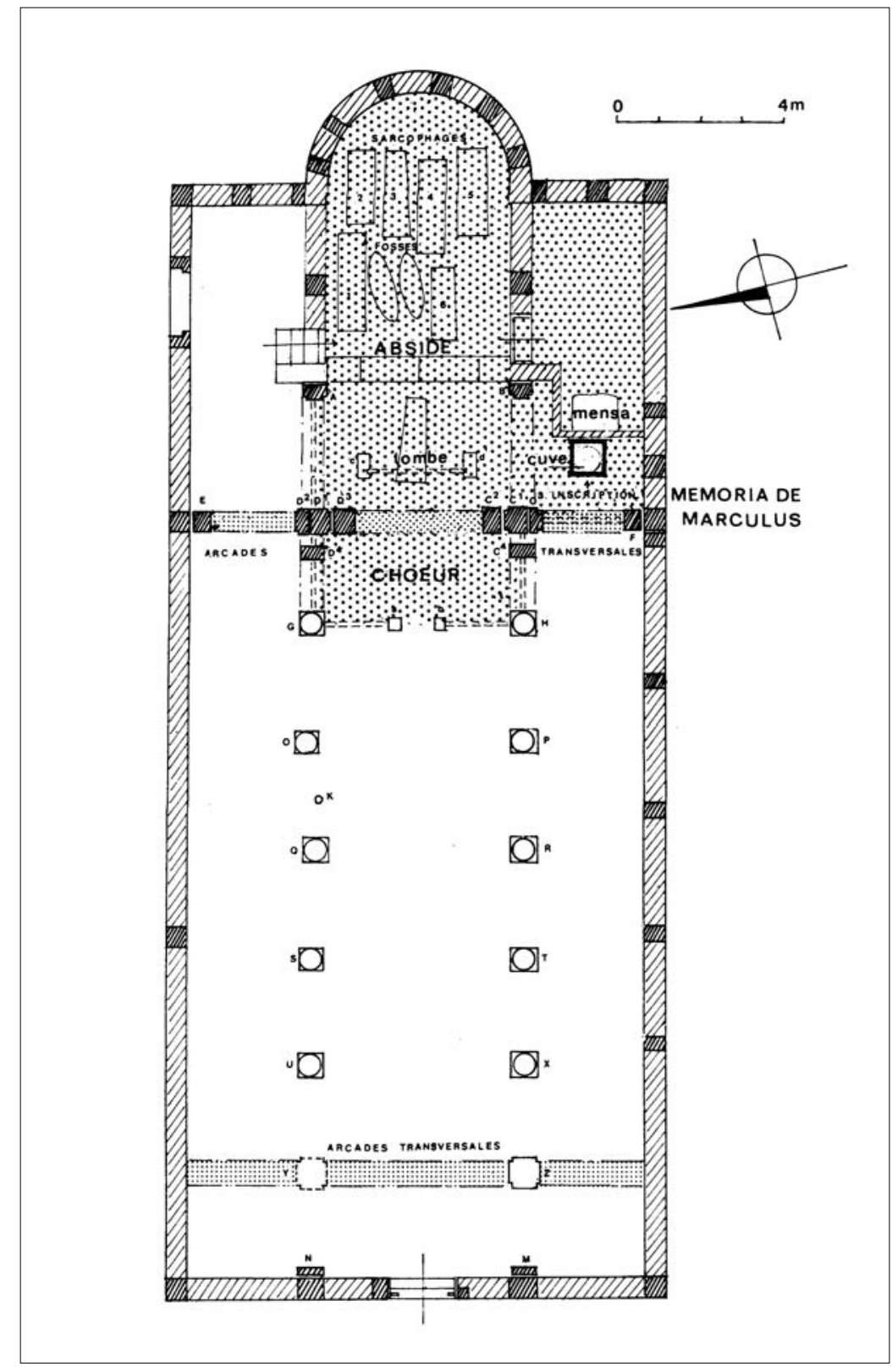

Fig. 17. Ksar el Kelb, plan restitué d'après Duval (GuI I., Duval N., CAILlet J.-P.,

Basiliques de l'Algérie, 2, Illustrations, 1992, pl. 141, 3). 


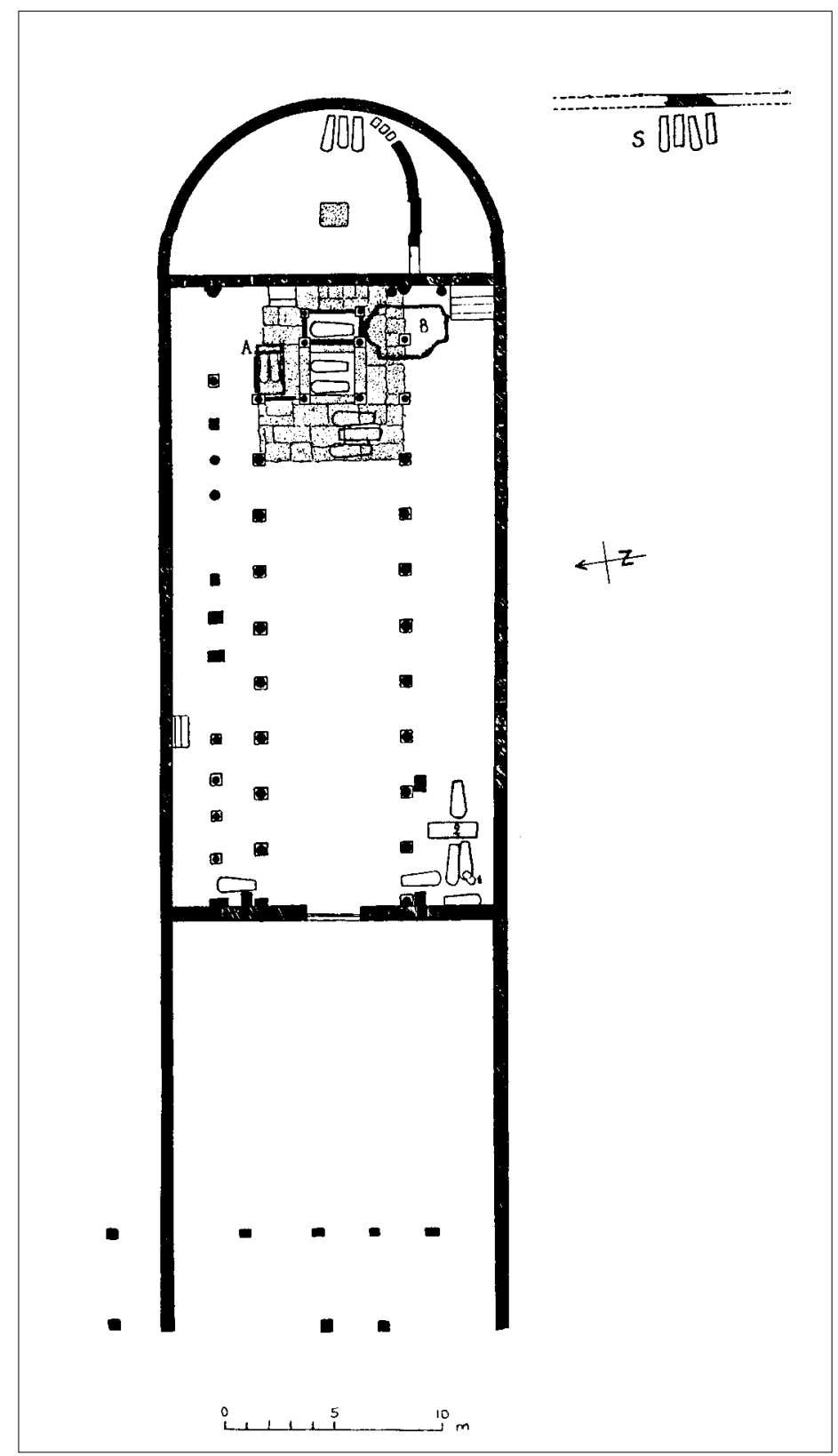

Fig. 18. Henchir Tarlist, plan d'après Labrousse (Gui I., Duval N., Caillet J.-P., Basiliques de l'Algérie, 2, Illustrations, 1992, pl. 81, 3). 
probablement à la chaux, disposé perpendiculairement à l'axe de l'église était en partie "encastré" dans le mur de soutènement de l'abside ${ }^{47}$ (fig. 5). Il était précédé d'un espace dallé large de $0,80 \mathrm{~m}$, lui-même en contrebas de $0,35 \mathrm{~m}$ par rapport à la nef.

C'est probablement encore un cas semblable qui apparait dans la basilique d'Henchir Tarlist. L'édifice, remanié à plusieurs reprises, comporte, au centre du chœur, deux tombes perpendiculaires à l'axe de l'église, enfouies $30 \mathrm{~cm}$ plus bas que le dallage du chœur - c'està-dire au même niveau que le sol des nefs - et placées sous un ciborium dont les bases subsistaient lors de la fouille (fig. 18). Elles étaient recouvertes par une dalle de 2,10 x 1,10 m, qui marque l'emplacement supposé de l'autel. Cependant, l'aménagement découvert immédiatement derrière rend l'interprétation plus complexe : quatre colonnes (?) reliées par des murets bâtis avec des débris divers étaient érigées autour d'un soubassement (2,65 x 1,42 $\mathrm{m})$ qui couvrait une tombe à $1,20 \mathrm{~m}$ de profondeur. Le fouilleur l'interprétait comme un autel tardif ${ }^{48}$, mais I. Gui se demandait s'il ne s'agissait pas plutôt d'un autel devant lequel se seraient groupées des inhumations privilégiées couvertes par un ciborium ${ }^{49}$. Il est là encore difficile de trancher, mais il est vrai que si la maçonnerie du dernier aménagement serait étonnante pour un autel, la profondeur de la tombe couverte par l'aménagement laisse un doute. Ceci d'autant plus que l'on a découvert sur le dé du piédestal de la colonne au sud-ouest du chœur une épitaphe (memoria Paterini eips.), attribuée d'après la graphie à la fin du Ive siècle ou au début du suivant, que M. Labrousse considère comme celle d'un évêque ${ }^{50}$ et qu'I. Gui met en relation avec l'un des deux sarcophages placés sous le ciborium $^{51}$. La situation de l'édifice dans une area cimétériale ${ }^{52}$, comme l'indiquent les tombes trouvées contre un mur au sud de l'édifice et celles, au même niveau et de même typologie, partiellement couvertes par le mur de l'abside, rendent vraisemblable l'existence d'une tombe considérée comme sainte dans l'église.

L'église d'Henchir Guesseria, enfin, peut aussi être classée dans cette série. Elle possédait, en avant de l'abside, juste devant le chancel, une fosse d'autel $(1,50$ x 1,20 m pour $1,00 \mathrm{~m}$ de haut) - plutôt qu'une crypte compte tenu des dimensions -, dont le fond était surcreusé d'une cavité (1,10/1,20 x 0,40 x prof. $0,60 \mathrm{~m})$ qui contenait une sépulture d'enfant (fig. 19 et 20). On hésite à y reconnaître une tombe sainte ou un dépôt de reliques ${ }^{53}$, mais on se trouve presque certainement en présence d'un aménagement lié au culte d'un saint ou d'un martyr.

47 SimON M., Henchir-el-Ateuch, 1934, p. 160, parle du "plâtre" qui les recouvrait primitivement.

48 LABRousse M., Henchir Tarlist, 1938, p. 232.

49 Gui I., Duval N., Caillet J.-P., Basiliques de l'Algérie, 1992, p. 133. Tout en faisant remarquer que l'aménagement serait exceptionnel, I. Gui signalait qu'il existe parfois des inhumations privilégiées protégées par une petite enceinte comme dans les églises 1 (porte de Lambèse), 7 ("cathédrale donatiste") et 11 de Timgad, et l'église 1 d'Haïdra.

50 LABRousse M., Henchir Tarlist, 1938, p. 242.

51 Gui I., Duval N., Caillet J.-P., Basiliques de l'Algérie, 1992, p. 133.

52 C'est aussi à cette area qu'il faudrait rattacher un puits desservant des loculi sur la droite du chœur (en B sur le plan), qui serait antérieur à l'église. Le puits, large de 3,00 m pour une profondeur de 4,00 m était percé, sur les parois nord-sud et ouest de deux étages de loculi, fermé par des tuiles (dedans, sépultures à la chaux). Certains contenaient des ossements calcinés et du mobilier, dont des bronzes monétaires brûlés - qui pourraient, selon LABROUSSE M., 1938, Henchir Tarlist, p. 239-240, appartenir au Ve-VIe siècle par leur taille. L'aménagement serait antérieur à la basilique : il a été réduit et le sol de l'église reposait sur une épaisse couche de déblais (1,00 m) qui couvrait la voûte du puits funéraire.

53 Duval N. et JanON M., Henchir Guesseria, 1985, p. 1095. 


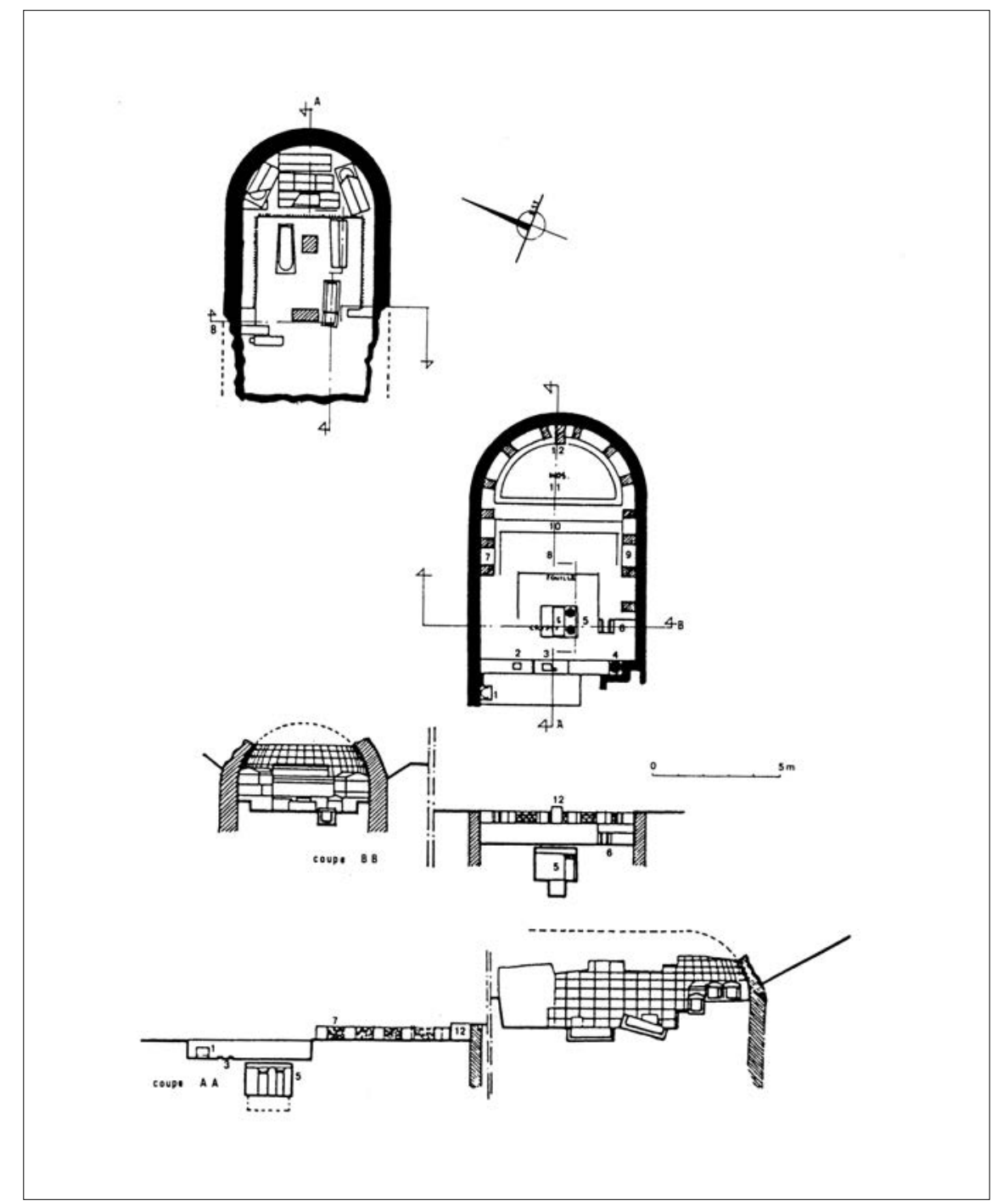

Fig. 19. Henchir Guesseria, plan, coupes transversale et longitudinale de Meunier publiés par Février (Gui I., Duval N., CAILlet J.-P., Basiliques de l'Algérie, 2, Illustrations, 1992, pl. 84,2). 


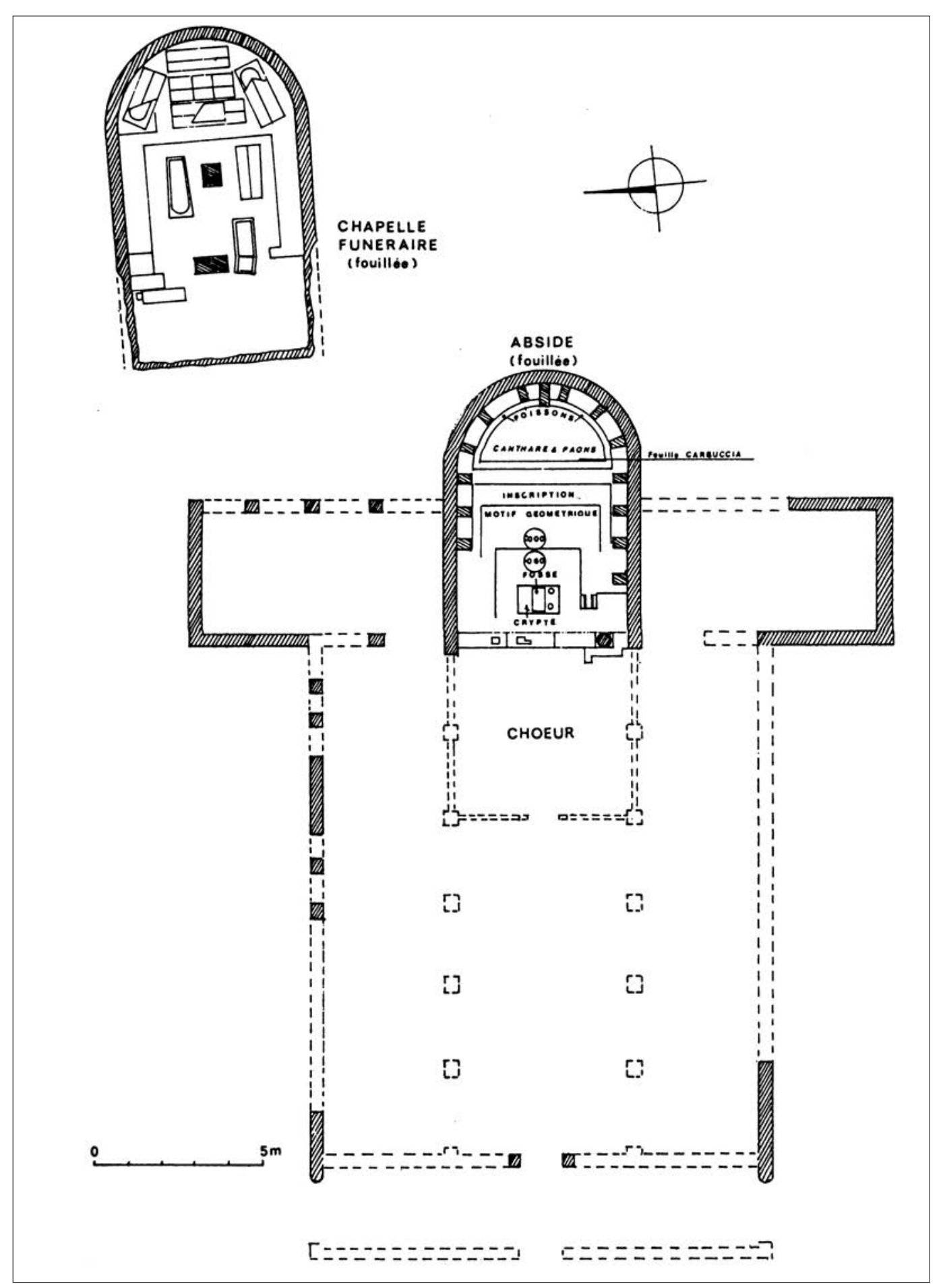

Fig. 20. Henchir Guesseria, essai de restitution du plan de l'église et de la chapelle par Duval (Gui I., Duval N., CaIllet J.-P., Basiliques de l'Algérie, 2, Illustrations, 1992, pl. 84,1). 
Quoi qu'il en soit, lorsqu'elles sont associées à l'autel, ces tombes sont directement liées par des restes matériels à la mémoire du saint. Il existe cependant d'autres formes d'aménagements qui permettent de rappeler sa mémoire, même lorsque le martyr ou le saint n'est pas physiquement présent. En effet, les témoignages épigraphiques désignent par le terme memoria, à l'origine lié au contexte funéraire, aussi bien la tombe sainte que la basilique ad corpus ou que le lieu commémorant la passion (qui ne contient pas nécessairement le corps du martyr), ou encore tout aménagement lié au culte martyrial sans lien immédiat avec la tombe du martyr. Édifices consacrés loin des tombes des martyrs, éléments du mobilier liturgique, reliques ou ex-votos en l'honneur des martyrs sont ainsi également désignés par le terme memoria ${ }^{54}$.

En Numidie, l'exemple le plus spectaculaire en est la memoria triconque de Tébessa, associée à une basilique de pèlerinage probablement dédiée à sainte Crispine ${ }^{55}$. Sur le flanc sud de l'église se dresse un édifice triconque, légèrement en contrebas de la basilique de la fin du IVe-début du V viècle, sur laquelle elle ouvre par un escalier (fig. 22). L'aménagement, sous cette forme, semble contemporain de la construction de l'église, mais il existait à l'origine un monument indépendant dont les fouilles ont révélé l'existence. Si l'architecture

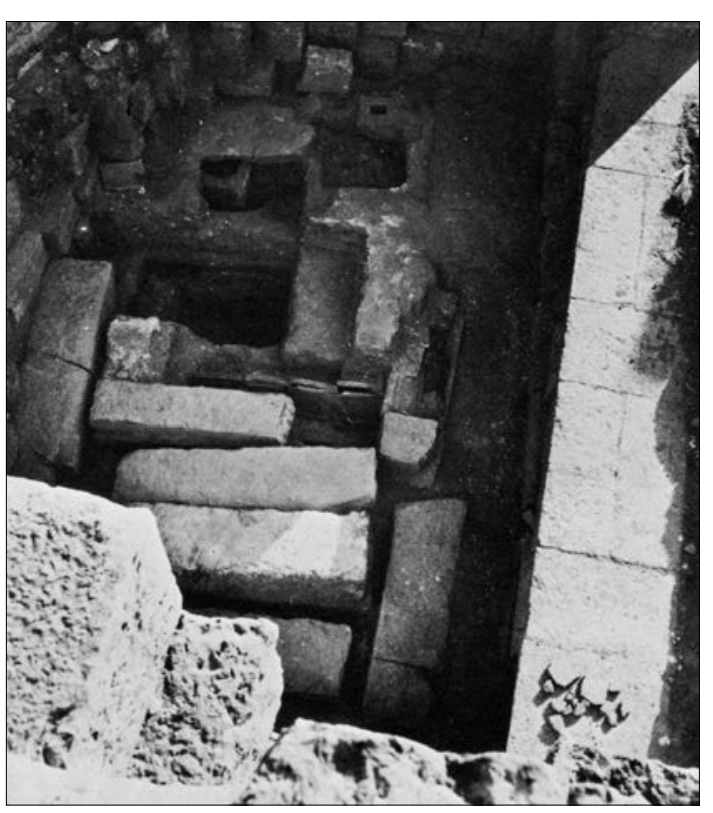
de cet édifice demeure inconnue, son développement est assez clair. Ce premier bâtiment était une memoria indépendante qui semble s'être implantée sur le lieu du martyre de sainte Crispine (et non sur sa sépulture qui n'a pas été retrouvée). Les niveaux les plus anciens dégagés ont permis de reconnaître, à l'intérieur, autour d'un espace vierge sanctifié plus tard par un dépôt de reliques ${ }^{56}$, huit sarcophages monolithes et deux tombes sous tuiles, dont le niveau était cohérent avec celui du reliquaire (fig. 21). L'ensemble était à l'origine scellé par un sol, qui fut couvert plus tard par un pavement de

Fig. 21. Tébessa, chapelle triconque, vue des fouilles sous la mosaïque (Duval Y., Loca sanctorum, I, fig. 88, 1982, p. 125).

755.

54 Voir le résumé des significations que donne DuVAL Y., Loca sanctorum, II, en conclusion, 1982, p. 753-

55 FÉVRIER P.-A., Salle tréflée, 1968, p. 190.

56 Le dépôt de reliques s'est fait dans un vase protégé par des tuiles, découvert sur le bord de cet espace vierge, au sud/sud-ouest. Cassé avant sa mise en place, le reliquaire contenait, mêlés à des traces de plâtre et à de la terre, un fragment d'os, des dents, deux morceaux de bronze et des restes de tissus, un bout d'épingle, trois morceaux du couvercle primitif du vase : cf. FÉVRIER P.-A., Salle tréflée, 1968, p. 184-189, repris par DUVAL Y., Loca sanctorum, I, 1982, p. 125. 


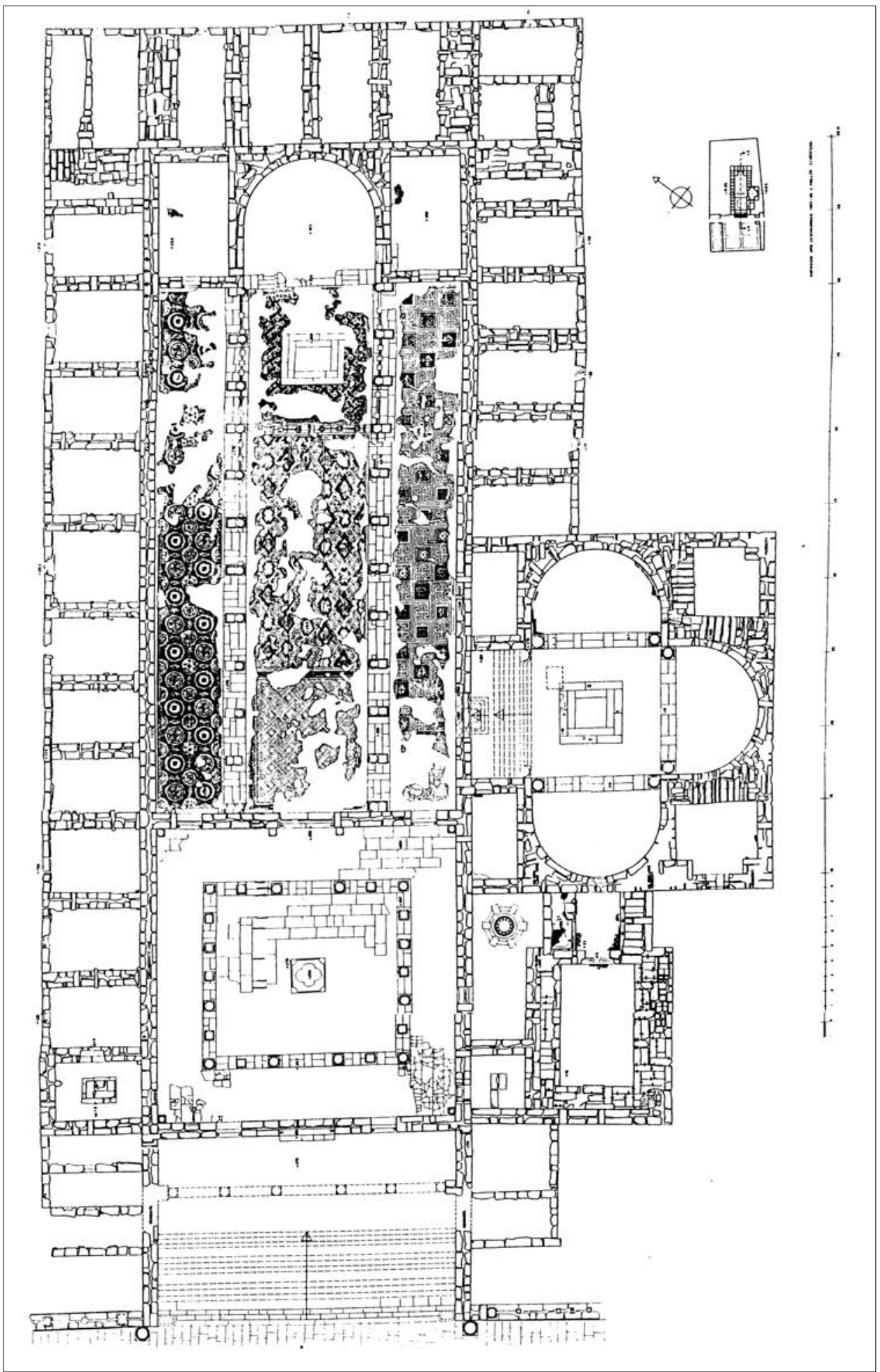

Fig. 22. Tébessa, plan détaillé du complexe d'après Christern et Müller

(Gui I., Duval N., CAIllet J.-P., Basiliques de l'Algérie, 2, Illustrations, 1992, pl. 151). 
mosaïque homogène et cohérent. Ce dernier fut ensuite endommagé par les tranchées de fondation creusées lors de la construction de la chapelle tréflée qui remplaça la première memoria. Deux monnaies de Constance II scellées entre le tapis de mosaïque et le sol plus ancien donnent le terminus post quem de 350.

L'inscription martyrologique ${ }^{57}$ placée au centre d'une couronne de laurier inscrite dans un carré sur le pavement adopte un formulaire d'épitaphe qui indique qu'elle ne commémore pas le dépôt de reliques. L'inscription ne se trouvait pas immédiatement audessus du reliquaire découvert, alors que le tapis de mosaïque est de conception unitaire. Elle était complétée par une inscription votive commémorant l'offrande du pavement par le diacre Novellus ${ }^{58}$, et par quatre à cinq épitaphes très simples, dont celles d'un lecteur et d'un diacre, à peu près orientées par rapport aux tombes sous-jacentes (fig. 23). Il faut donc supposer, comme l'a démontré Y. Duval ${ }^{59}$, l'existence, non d'une vénération du reliquaire, mais celle d'un lieu suffisamment vénéré, dès la première moitié du IVe siècle, pour attirer des tombes du clergé avant même le dépôt de reliques. Ce lieu vénéré correspond à un

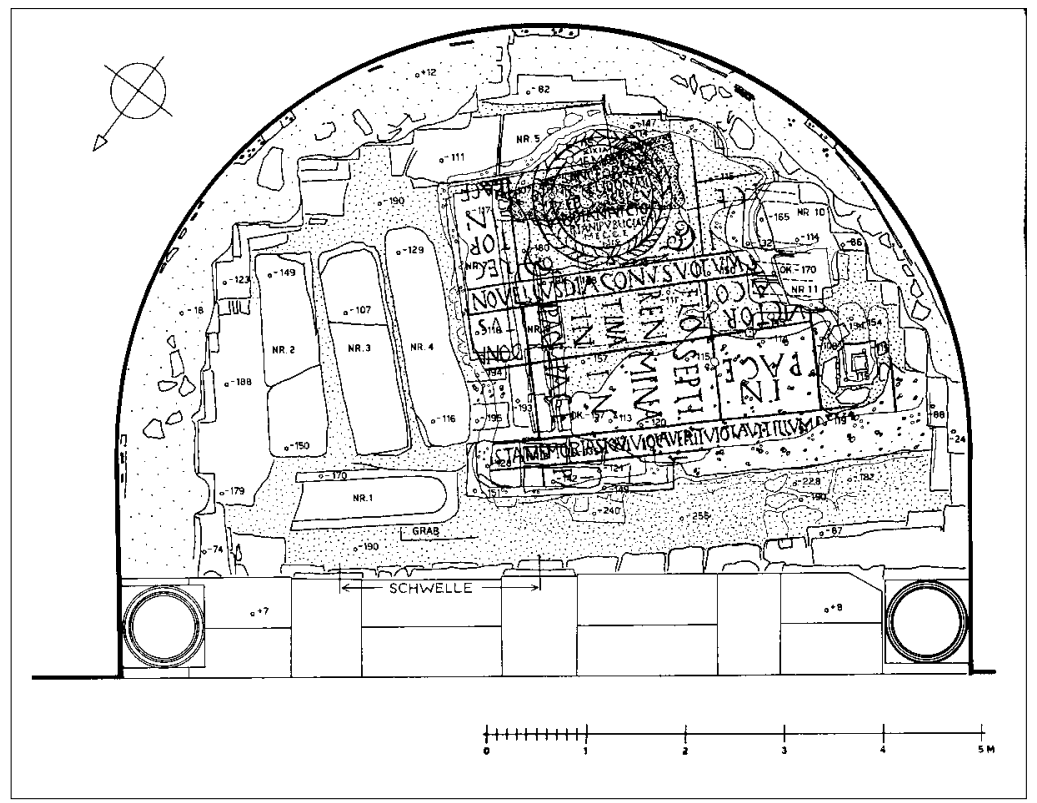

Fig. 23. Tébessa, triconque, les états successifs de l'abside médiane d'après Christern (Duval Y., Loca sanctoum, I, fig. 86, 1982, p. 124).

57 XI k(alendas) ian(uarias) / memoria / sanctorum / He[r]acli, Donati, / Zeb[b]ocis, Secu/ndiani, Victo/ riani, Publiciae, /Megge/rais (le 11 des kalendes de Janvier, souvenir des saints Heraclius, Donatus, Zebboc, Secundanus, Victorianus, Publicia, Megginus) ; cf. DuVAL Y., 1982, Loca sanctorum, I, p. 126.

58 Novellus diaconus votum s[olvit ... ], [...] ista memoria si quis violaverit violavit illum Deus; cf. DUVAL Y., Loca sanctorum, I, 1982, p. 125.

59 DUVAL Y., Loca sanctorum, I, 1982, p. 127 ; voir aussi FÉVRIER P.-A., Inhumation privilégiée, 1986, p. 17. 
cénotaphe, qui explique le formulaire funéraire et la formule de malédiction pour le violateur éventuel de cette memoria (ista memoria qui apparaît dans la bande sous l'inscription martyrologique). Dans ce cas, la memoria ne se trouve pas sur la tombe des martyrs - probablement Crispine et ses compagnons ${ }^{60}$ - mais probablement sur le lieu de leur martyre. Les tombes découvertes sont donc dans ce cas des tombes privilégiées des membres du clergé 61.

On rencontre dans les églises d'Afrique d'autres aménagements qui témoignent d'une vénération du saint détachée partiellement de la tombe des martyrs. Y. Duval a montré que certains plateaux de tables, inscrits, du fait même du formulaire épigraphique, ne pouvaient être ni des mensae funéraires, ni des bases d'autel ayant un loculus à reliques, mais des offrandes faites à la mémoire du martyr ${ }^{62}$. Ces ex-votos portent souvent un décor qui évoque une table de repas, comme la mensa marturum découverte dans l'église 2 d'Henchir Bou Takrematen, ornée de quatre coupelles et d'une "assiette" centrale (fig. 24). Datée des IVe-Ve siècles d'après la graphie de l'inscription, la dalle est interprétée par Y. Duval comme une table d'oblation en l'honneur de martyrs, qui était placée sur un monument commémoratif plutôt qu'utilisée comme base d'autel ${ }^{63}$.

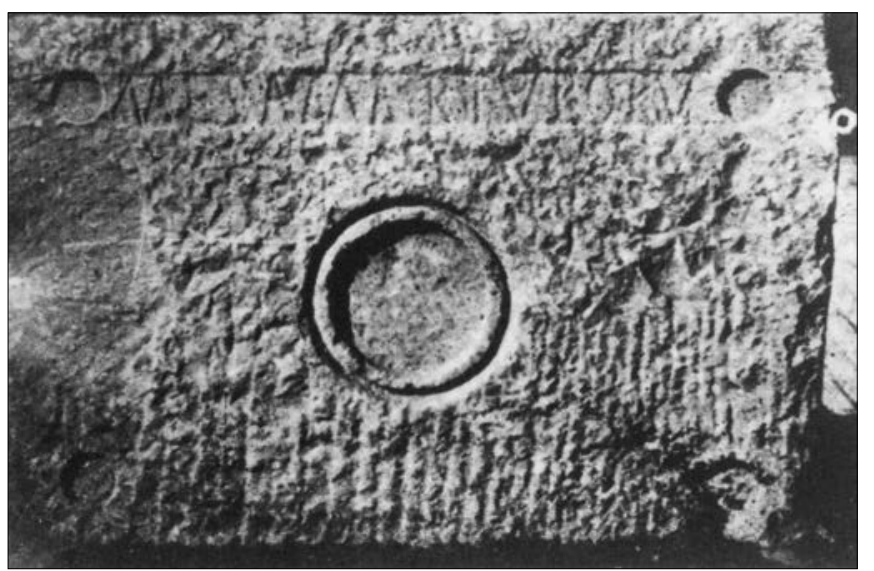

Fig. 24. Henchir Bou Takrematen, mensa marturum

(Gui I., Duval N., CAIllet J.-P., Basiliques de l'Algérie, 2, Illustrations, 1992, pl. 94,3).

60 L'inscription est datée du 11 des calendes de janvier, soit le 22 décembre. Or, le martyrologe de Tébessa mentionne à la date du 5 janvier le martyre de Crispine et de ses compagnons, dont les noms - d'ailleurs transmis par des listes partiellement corrompues - sont très voisins, selon FÉVRIER P.-A., Salle tréflée, 1968, p. 189-190, des noms mentionnés sur la mosaïque. L'auteur en déduit que la memoria de Tébessa a probablement été érigée sur le lieu du martyre de Crispine et de ses compagnons, interprétation qu'accepte DUVAL Y., Loca sanctorum, I, 1982, p. $127-128$.

61 Sur les sépultures privilégiées, voir infra.

62 Duval Y., Loca sanctorum, I, chap. IV “Mensa marturum”, 1982, p. 530-542.

63 Duval Y., Loca sanctorum, I, 1982, p. 253-254. 
Que le saint soit présent ou non par des vestiges matériels, les aménagements liés à sa vénération ont rapidement attiré des sépultures. La présence des tombes dans et autour des églises est l'une des caractéristiques marquantes des basiliques africaines, mais aussi d'Occident en général. L'ampleur du phénomène prend une physionomie différente selon les époques : dans les édifices les plus tardifs, l'accumulation des tombes dans les basiliques urbaines est spectaculaire, mais jusqu' au milieu du ve siècle, l'inhumation dans l'église reste le privilège d'un nombre restreint d'individus ; les sépultures se concentrent plutôt autour de l'église ${ }^{64}$. La tombe privilégiée est bien sûr celle du martyr, qui, dès l'origine, fait l'objet d'un traitement spécifique (cénotaphe, area, basilique ad corpus, cf. supra), mais aussi toute tombe proche de la tombe sainte, qui retire les bienfaits de sa présence. Sans l'approuver, Augustin témoigne en effet de la ferveur dont jouissaient les inhumations ad sanctos pour les Chrétiens de son temps. À ses yeux, le voisinage d'une tombe sainte ne pouvait rien amener en soi, puisque seules comptent les prières qui recommandent le défunt à Dieu ; cependant l'évêque d'Hippone admet que les sépultures ad sanctos pouvaient bénéficier d'un effet bénéfique dans la mesure où les prières des vivants pour les morts se trouvent redoublées par la proximité d'une sainte sépulture ${ }^{65}$.

De ce point de vue les églises de Numidie ne présentent guère de spécificités par rapport au reste des provinces africaines. Des sépultures privilégiées y apparaissent le plus souvent sans qu'on puisse identifier le défunt, à l'exception des épitaphes qui apparaissent sur le pavement de la chapelle tréflée de Tébessa et de l'inscription conservée sur le dé du piédestal d'une colonne de l'église d'Henchir Tarlist, qui nomment des membres du clergé 66 .

En l'absence d'inscription, distinguer une tombe ad sanctos d'une tombe sainte n'est guère aisée ; cependant, certains emplacements, comme l'abside, possèdent un prestige plus important que d'autres. À Ksar el Kelb, elle renfermait, disposés dans l'axe de l'édifice, six sarcophages auxquels s'ajoutaient deux tombes à fosse. Le lien des tombes avec l'abside et l'organisation architecturale de l'édifice apparaît évident puisqu'elles ont entraîné la surélévation du sol de l'abside (fig. 17). Cela conduisait P. Courcelle à considérer que ces sépultures ne renfermaient pas les corps de simples fidèles, mais ceux de saints, qu'il proposait d'identifier aux neuf évêques donatistes martyrisés en même temps que Marculus ${ }^{67}$. L'église n'aurait possédé que des reliques de ce dernier ${ }^{68}$, puisque son tombeau présumé faisait l'objet d'un pèlerinage à Nova Petra, au nord de Batna. En l'absence d'épitaphe, il est difficile de soutenir l'interprétation ; il reste incontestable qu'il s'agit de tombes privilégiées, mais peut-on les qualifier de saintes ou même d'ad sanctos?

64 DuVAl Y., Loca sanctorum, II, 1982, p. 513 ; FÉVRIER P.-A., Inhumation privilégiée, 1986, p. 19-20.

65 AUgustin, De cura pro mortuis gerenda, IV, 6 ; V,7 ; XVIII,22 ; cf. DUVAL Y., Loca sanctorum, II, 1982. p. $517-518$

66 Un évêque Paternus à Henchir Tarlist, cf. LABROUSSE M., Henchir Tarlist, 1938, p. 242 ; le diacre Novellus, le diacre Victor, le lecteur Donatus à Tébessa, cf. FÉVRIER P.-A., Salle tréflée, 1968, p. 177 ; ID., Inhumation privilégiée, 1986,p. 17.

67 Courcelle P., Ksar el-Kelb, 1936, p. 180.

68 CourCelle P., Ksar el-Kelb, 1936, p. 183. 
Une situation voisine apparaît dans la chapelle d'Henchir Guesseria : trois sarcophages à couvercle en bâtière sont placés dans l'abside perpendiculairement à l'axe de l'édifice, auxquels s'ajoutent deux autres sarcophages disposés en oblique dans l'espace restant ; dans la nef, trois sarcophages conservés dans l'axe de l'édifice évoquent des sépultures privilégiées ${ }^{69}$ (fig. 19 et 20 ). Il en va de même à Henchir Deheb où la tombe placée dans l'abside, dans l'axe de l'église ${ }^{70}$, n'est manifestement pas associée à l'autel, qui est restitué très en avant dans la nef, dans la quatrième travée en comptant depuis l'abside (fig. 25).

La proximité de l'autel est un emplacement évidemment recherché pour ces tombes privilégiées, sans qu'on sache toujours si celui-ci était effectivement lié à une sépulture martyriale. À Henchir Tarlist, on ne sait si les sépultures protégées par le ciborium supposé sont des tombes saintes (si on admet la restitution de l'autel au-dessus, cf. supra) ou de simples tombes privilégiées. Le doute n'est guère permis, en revanche, pour les trois tombes enterrées sous le dallage perpendiculairement à l'axe de l'église juste devant les précédentes, ni pour celles découvertes immédiatement sur la gauche du chœur (en A sur le plan) (fig. 18). Ces dernières étaient disposées dans un caveau funéraire $(1,10 \mathrm{~m}$ x 2,00 m) à $1,50 \mathrm{~m}$ de profondeur, qui était signalé par un renfoncement dallé de 2,00 x 1,50 m dans le sol de l'édifice, $20 \mathrm{~cm}$ en contrebas du pavement du chœur. Les tombes, non violées, renfermaient un mobilier relativement riche, ce qui mène $\mathrm{M}$. Labrousse à les considérer comme les sépultures “de pieux personnages entourés d'une certaine vénération" 71 . On est bien sûr tenté de les interpréter comme des sépultures privilégiées, mais il faudrait connaître la chronologie relative du caveau et de l'église. Quoi qu'il en soit, même si le caveau est plus ancien, les sépultures étaient suffisamment prestigieuses pour que leur emplacement soit signalé au sol de l'église. De l'église Est de Djemila, érigée dans une zone cimétériale, il ne reste qu'une crypte et une partie des nefs de l'église, où subsistent plusieurs tombes (fig. 9). Celle qui est placée contre le mur de la crypte ${ }^{72}$, placée dans l'axe de la nef, à un endroit qui peut avoir été proche également de l'autel, jouit manifestement d'un emplacement privilégié.

À Timgad, à deux reprises, la nef contient des sépultures, qui, par les aménagements spécifiques dont elles ont fait l'objet, apparaissent comme des tombes privilégiées. Dans l'église érigée dans la nécropole proche de la porte de Lambèse, au Nord-Ouest, un

69 Selon Duval N. et JanON, M., Henchir Guesseria, 1985, p. 1091.

70 Cf. Gui I., Duval N., CAillet J.-P., Basiliques de l'Algérie, 1992, pl. 143, la coupe et plan de Laout, 1936, publiés par Leschi.

71 LABRousse M., Henchir Tarlist, 1938, p. 239.

72 Duval N. et FÉvrier P.-A., Basilique cimétériale de l'Est, 1991, p. 133-141. Cependant, les coupes qui permettraient de juger des dénivellations font défaut. 


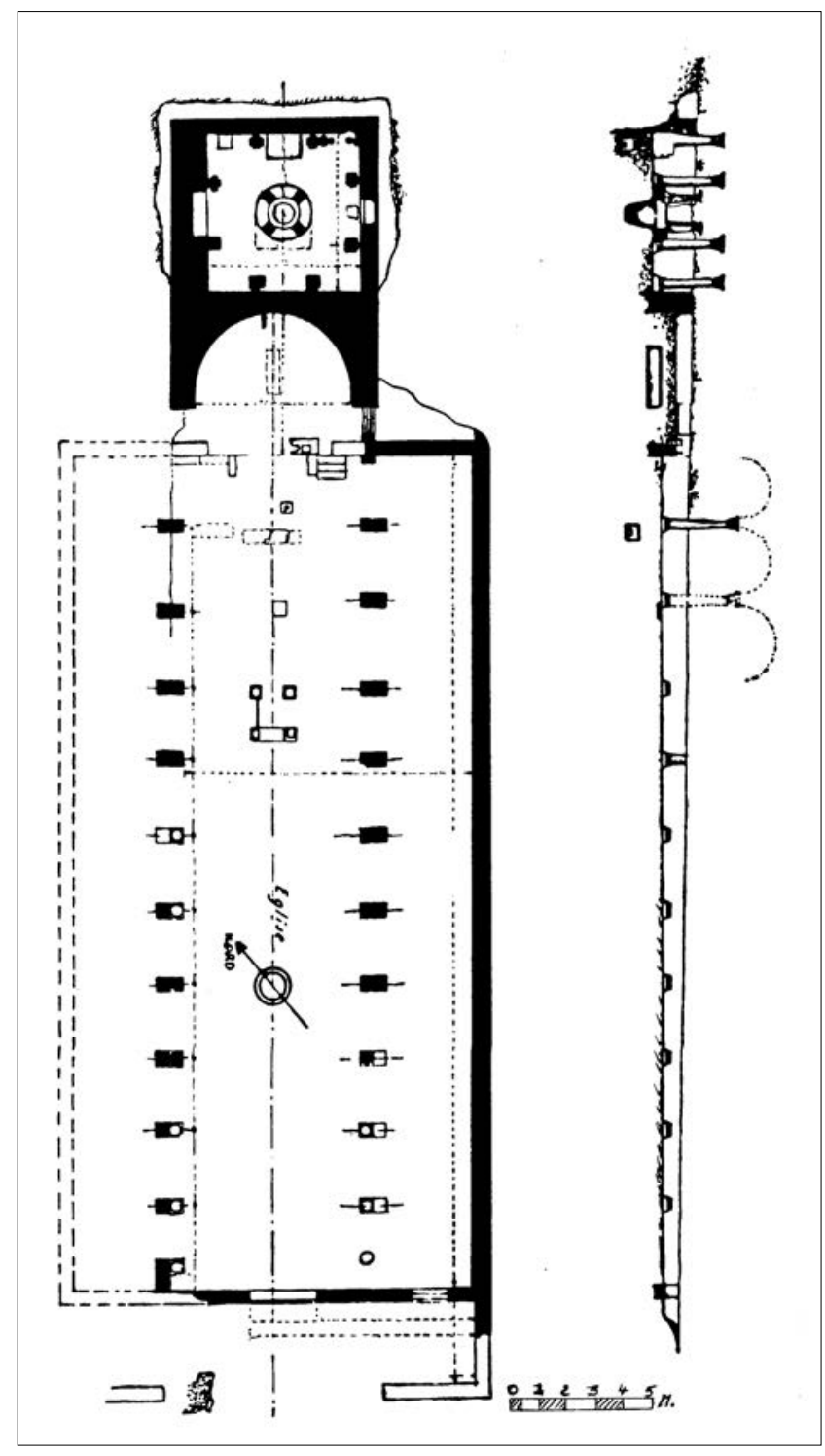

Fig. 25. Henchir Deheb, plan et coupe d'après Laout (Gui I., Duval N., CAillet J.-P.,

Basiliques de l'Algérie, 2, Illustrations, 1992, pl. 143,1). 
sarcophage $(1,60$ x 0,90 m) à couvercle en bâtière et acrotères était placé au centre de la nef centrale, légèrement décalé vers la droite (Nord-Est), dans une fosse au centre d'une surface dallée (3,50 x 3,58 m), elle-même protégée par un chancel (fig. 26). L'aménagement et "la poignée d'ossements" d'enfants que contenait le sarcophage ${ }^{73}$ a conduit à des interprétations diverses. Selon M. Christofle, le fouilleur, le sarcophage était recouvert d'une dalle - qu'il n'a pas retrouvée - au-dessus de laquelle il restituait un autel. N. Duval, assimile ces ossements d'enfants à des reliques ou au "résultat d'une réduction de plusieurs corps" tout en privilégiant l'hypothèse d'un sarcophage visible pouvant être touché ${ }^{74}$. P.-A. Février y voit plutôt la réduction d'une sépulture, donc une sépulture secondaire, dans

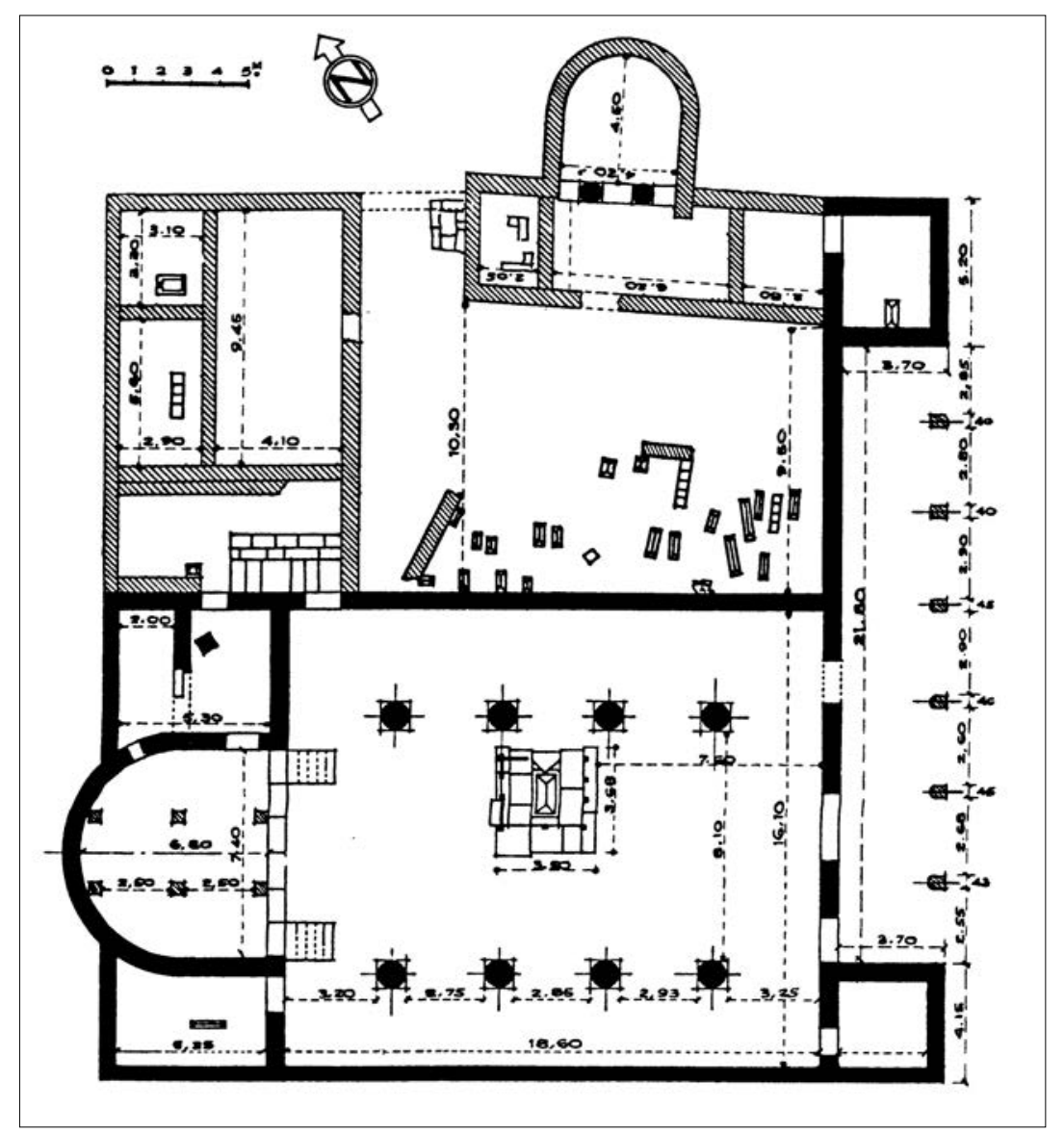

Fig. 26. Timgad, église de la nécropole de la Porte de Lambèse (église 1), plan d'après Christofle (Gui I., Duval N., CaIllet J.-P., Basiliques de l'Algérie, 2, Illustrations, 1992, pl. 127,1).

73 Christofle M., Rapport sur les travaux, 1938, p. 366.

74 Duval N., Haïdra, II, 1981, p. 190. 
une basilique martyrologique ${ }^{75}$. Il reste difficile de trancher : privilégiée, la tombe l'est sûrement par sa protection par un chancel ; en revanche, il est difficile de dire s'il s'agit d'une tombe sainte - ou même d'un dépôt de reliques. On ne comprend pas bien pourquoi l'aménagement occupe cette position excentrée dans la nef. Par ailleurs, son emplacement même à l'intérieur de la basilique et non dans la cour au nord-est de l'édifice lui confère un statut particulier qu'il est difficile de définir plus précisément. Un aménagement voisin apparaît dans l'église 7 de Timgad (“cathédrale donatiste") : dans la nef, à la hauteur des 7e et $10^{\mathrm{e}}$ colonnes, presque dans l'axe de la chapelle à crypte plus tardive qui flanque l'édifice à l'Est, deux stylobates de pierre délimitent un emplacement privilégié approximativement carré de 2,65 m de côté. Au centre de cette area, perpendiculairement à l'axe de la nef de l'église et légèrement décalé vers la gauche (l'Est) à la limite entre la nef centrale et le collatéral, un sarcophage dont seul le couvercle en bâtière affleurait était enfoui dans le sol de l'édifice (fig. 27 et 28). Le couvercle était percé d'une ouverture en forme d'entonnoir dans laquelle a été trouvé un élément de bronze en forme de passoire. L'aménagement, qui

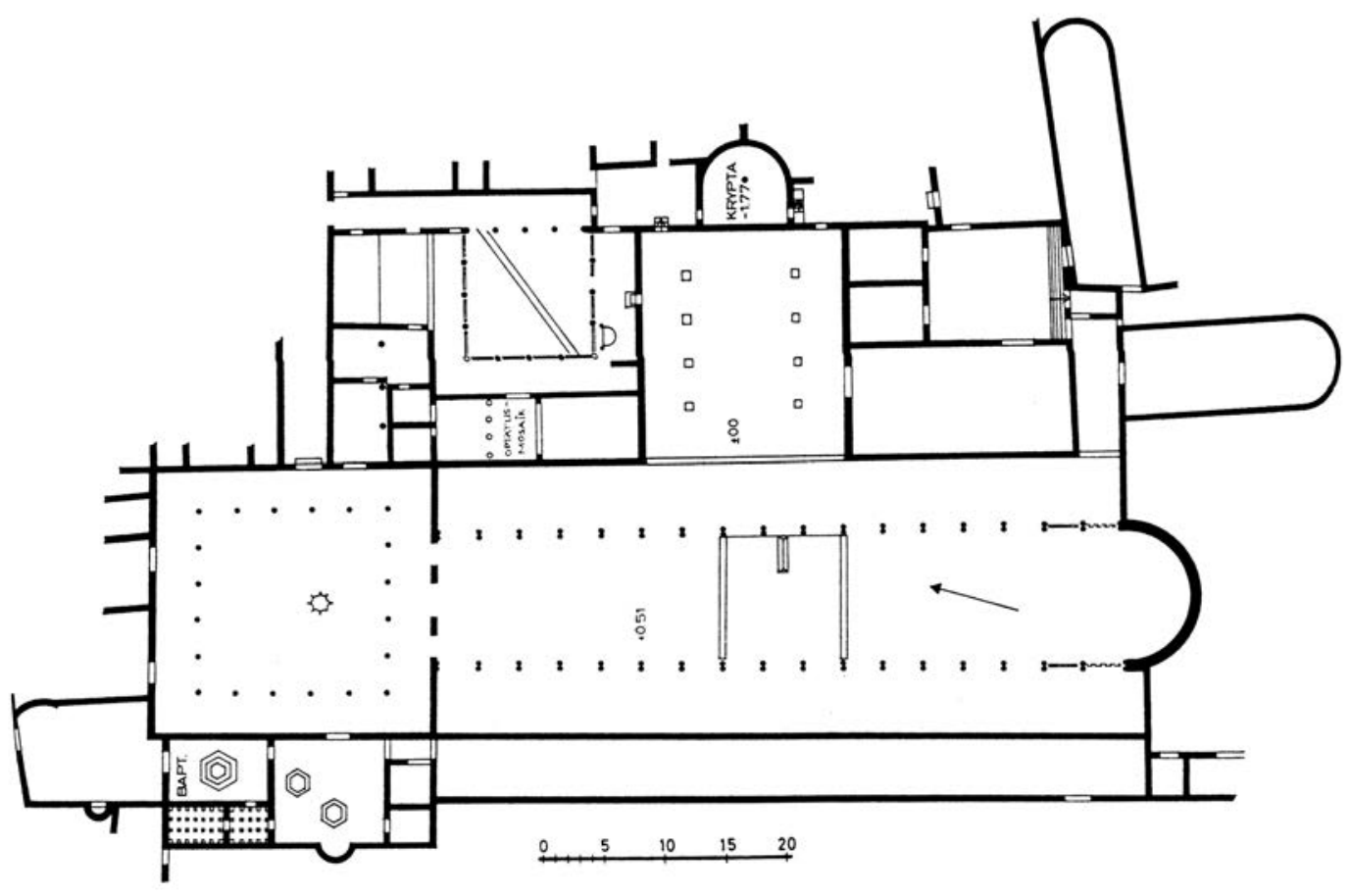

Fig. 27. Timgad, églises 7-8 ("cathédrale donatiste")

(Gui I., Duval N., Caillet J.-P., Basiliques de l'Algérie, 2, Illustrations, 1992, pl. 132,2).

75 FÉVRIER P.-A., Inhumation privilégiée, 1986, p. 16-17. 


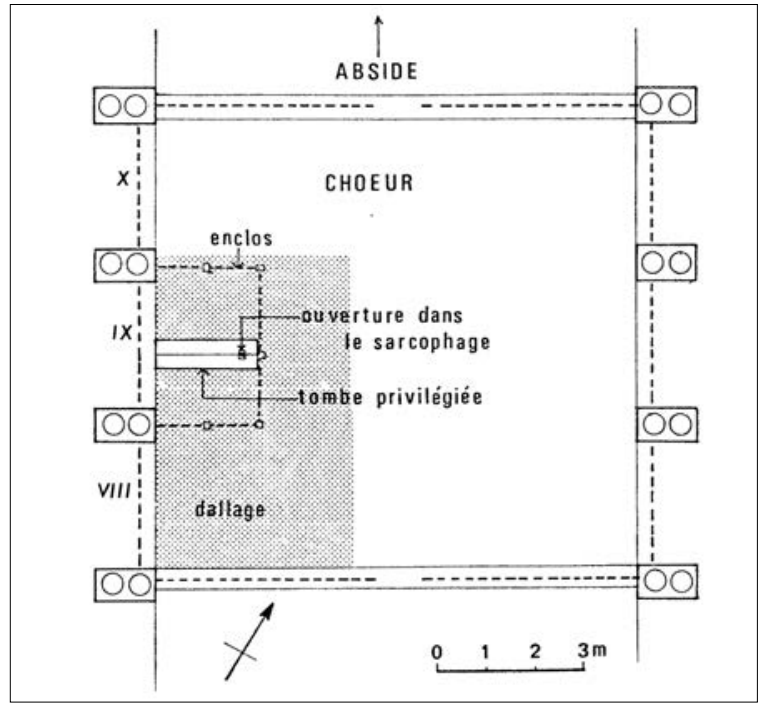

Fig. 28. Timgad, église 7 ("cathédrale donatiste"), chœur et sépulture privilégiée d'après un croquis de Duval (Gui I., Duval N., Caillet J.-P., Basiliques de l'Algérie, 2, Illustrations, 1992, pl. 133,5).

se trouvait à l'aplomb de la bouche du squelette que renfermait le sarcophage, a été interprété comme un dispositif à libations ${ }^{76}$. On pourrait hésiter à considérer la sépulture comme une tombe sainte, mais aussi bien P.-A. Février que N. Duval s'accordent à n'y reconnaître qu'une sépulture privilégiée ${ }^{77}$.

Quoi qu'il en soit, ces sépultures révèlent des pratiques funéraires - ici les libations dans ce dernier exemple, mais aussi la vénération de martyrs et la recherche de la proximité de leur tombe pour d'autres sépultures - dont les sources textuelles ne se font guère l'écho, hormis les passages célèbres d'Augustin, qui s'érige contre les banquets célébrés sur la tombe des martyrs, héritage lointain d'un culte rendu aux morts ${ }^{78}$.

Ce culte des martyrs qui s'est développé à l'origine en milieu funéraire prend - au moins à partir du ve siècle - un aspect plus liturgique avec le dépôt, sous ou dans l'autel, de reliques qui sont prises comme le substitut des corps des martyrs. Le culte des reliques devient alors un élément essentiel de la piété populaire, dont les vestiges archéologiques témoignent davantage que les sources écrites. Augustin y fait de nombreuses allusions dans ses sermons, mais elles témoignent plus du climat de ferveur populaire vis-à-vis des reliques qu'elles ne précisent leur nature ou leur emplacement ${ }^{79}$.

76 Marrou H.-I., Survivances païennes, 1978, p. 226.

77 FÉVRIER P.-A., Tombe chrétienne, 1984, p. 167, sans argumentation, et ID., Inhumation privilégiée, 1986, p. 16 ; DuVAL N., Haïdra, II, 1981, p. 188-189.

78 Cf. notamment la lettre 22, 6 envoyée à Aurelius de Carthage en 392. Pour les prises de position d'Augustin au sujet du refrigerium, cf. le résumé dans MARROU H.-I., 1979, Inscription chrétienne, p. 267-269.

79 Voir à ce sujet l'analyse de DuVAL Y., Loca sanctorum, II, 1982, p. 543-547. 
Les témoignages archéologiques des dépôts de reliques sont à priori nombreux dans les églises de Numidie ${ }^{80}$, mais on est frappé du peu d'exemples qui peuvent remonter à l'époque d'Augustin. Peut-être est-ce dû au hasard des découvertes archéologiques qui ont fourni peu d'inscriptions remontant à ces périodes 81 et à l'absence d'éléments stratigraphiques fiables du fait de l'ancienneté des fouilles. Ainsi, dans l'église d'Et Toual, l'auge de pierre $(0,80 \times 0,50 \mathrm{~m})$ contenant un reliquaire en terre cuite qui fut découverte au milieu du soubassement de l'autel par le commandant Massié en 1882 est attribuée sans argument précis aux IV $\mathrm{IV}^{\mathrm{e}} \mathrm{V}^{\mathrm{e}}$ siècles. Dans l'église 2 d'Henchir Bou Takrematen, le seul élément de datation est fourni par une mensa marturum attribuée à la même époque d'après la graphie de l'inscription. Mais l'indice suffit-il à dater le dépôt des reliques conservées dans l'urne d'albâtre découverte à l'intérieur d'un loculus aménagé dans la face antérieure du mur de soutènement de l'abside (fig. 29) ? La même question se pose pour le coffret découvert à Dalaa daté du IVe siècle par Gsell et Monceaux, dont l'usage comme reliquaire ne remonte pas nécessairement à cette époque ${ }^{82}$. Seule l'inscription gravée sur le chapiteau retaillé utilisé comme reliquaire qui fut découvert sous l'autel dans l'église d'Henchir elAbiod semble effectivement pouvoir être attribuée d'après la paléographie à la fin du IVe ou au début du ve siècle ${ }^{83}$.

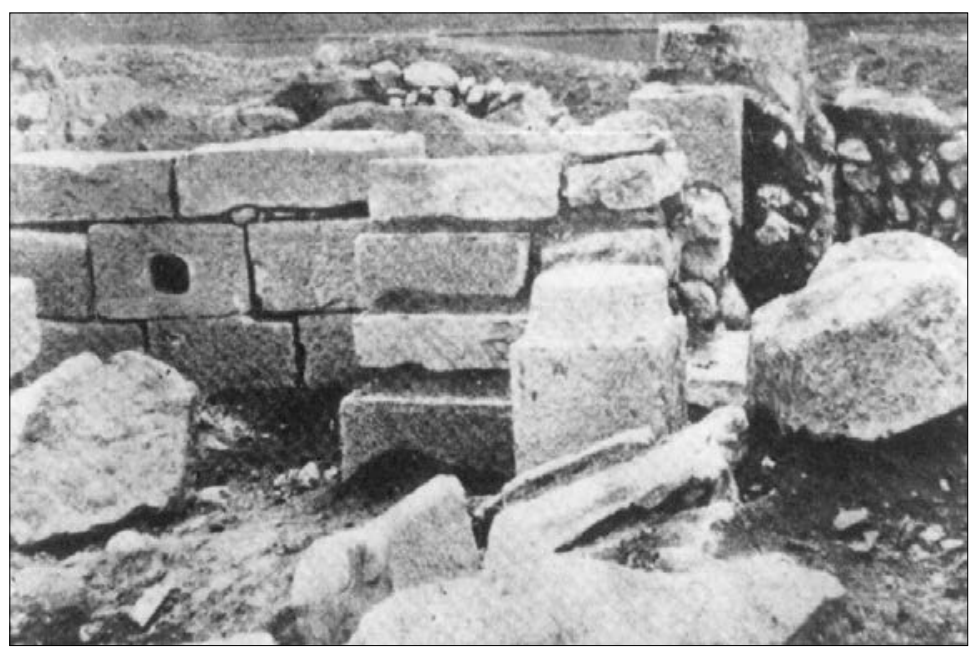

Fig. 29. Henchir Bou Takrematen 2, mur de soutènement de l'abside et escalier sud (cl. Berthier ; Gui I., Duval N., CAILlet J.-P., 1992, Basiliques de l'Algérie, 2, Illustrations, pl. 94).

80 Berthier A., Logeart F., Martin M., Numidie Centrale, s. d. [1942].

81 Duval Y., Loca sanctorum, II, 1982, p. 551, rappelle que la plupart des inscriptions liées au dépôt de reliques se répandent surtout à la fin du ve siècle et à l'époque byzantine ; elle le relie au fait que les saints dont les reliques circulent alors viennent de loin, d'où la nécessité de les identifier, contrairement aux saints locaux qui étaient connus de tous.

82 Duval Y., Loca sanctorum, I, n 76, 1982, p. 160-163.

83 Duval Y., Loca sanctorum, I, n 67, 1982, p. 144-145. 
La même incertitude prévaut pour les autres édifices dans lesquels des reliques ont été retrouvées : si leur construction peut être ancienne, aucun élément ne vient préciser la date de leur dépôt. Ainsi, l'église Nord de Djemila et sa crypte remontent probablement à la fin du Ive ou au début du ve siècle. Dans la crypte était conservé un massif maçonné de $1,48 \mathrm{~m}$ de côté dans lequel $\mathrm{P}$. Monceaux et $\mathrm{O}$. Nußbaum ont reconnu un autel ${ }^{84}$, mais que J. Christern a identifié comme un support pour un coffre à reliques, celles des prédécesseurs de l'évêque Cresconius, qui est mentionné dans une inscription sur le pavement de l'église Sud ${ }^{85}$. L'identification de Cresconius reste débattue : on admet traditionnellement qu'il s'agit de l'évêque qui signe en 411 au concile de Carthage, mais P.-A. Février considère que l'inscription se réfère à un Crescens ou Cresconius qui vivait au $\mathrm{VI}^{\mathrm{e}}$ siècle, ce qui coïnciderait mieux avec la graphie de l'inscription et le style du pavement ${ }^{86}$. Rien, dès lors, ne permet de dater avec assurance le dépôt des reliques.

L'église de Ksar el Kelb, datée d'après la mention épigraphique de Marculus qui est identifié au martyr donatiste mort en 347 , soulève le même embarras. Le dépôt de reliques n'est de toute façon pas placé sous l'autel majeur de l'église et l'installation présente des incohérences. À l'extrémité orientale du collatéral sud de l'édifice était aménagé un petit monument commémoratif protégé par un chancel, constitué d'une cuve $(0,56 \mathrm{~m}$ de haut, diam. $0,58 \mathrm{~m}$ ) encadrée de quatre plaques de pierre dont l'une portait une inscription la désignant expressément comme une memoria (memoria domni Marchuli) (fig. 17). Derrière cette memoria, dans la sacristie sud dont elle était séparée par un fin muret au tracé conjectural, les fouilles de P. Courcelle ont mis au jour, en 1935, une mensa de type funéraire, en plâtre, établie sur un massif de maçonnerie qui était creusé d'une cavité ovoïde, dans laquelle on a trouvé des débris d'os et de verre. Courcelle conclut à un dépôt de reliques violé - la mensa aurait alors servi de reliquaire - et considère la cuve de la memoria de Marculus comme un bénitier ${ }^{87}$. L'interprétation n'emporte pas vraiment l'adhésion : on se demande pourquoi un bénitier serait désigné du terme memoria. Il est clair cependant que l'installation n'a pas servi non plus pour un dépôt de reliques : Y. Duval rappelle que le formulaire employant le terme memoria au singulier, sans être précédé de hic, se réfère bien à une installation martyriale, mais ne désigne pas le loculus ${ }^{88}$. On est embarrassé pour interpréter l'installation, dont la chronologie reste obscure : s'il apparaît que les deux fouilleurs successifs de l'édifice s'accordent à considérer l'aménagement de la memoria comme postérieur à la construction de la basilique ${ }^{89}$, la chronologie relative de la mensa et de la memoria reste à déterminer. En effet, le muret dans lequel vient s'encastrer la mensa p. $182-183$

84 MoncEauX P., Découverte d'édifices chrétiens à Djemila, 1922, p. 387 ; NussBaum O., Altar, 1965,

85 CHRISTERn J., Tebessa, 1976, p. 137-144. L'auteur, p. 142-143 et note 51 p. 142, se fonde sur l'inscription dite de Cresconius sur le pavement du chour de l'église Sud qui rappelle que l'évêque a tiré de l'oubli les restes de ses prédécesseurs et les a placés sur et non sous des autels.

86 Sur ces problèmes de datation, voir le résumé dans GuI I., Duval N., CAILlET J.-P., Basiliques de l'Algérie, 1992, p. 93 et surtout p. 98.

87 Courcelle P., Ksar el-Kelb, 1936, p. 177.

88 Duval Y., Loca sanctorum, I, 1982, p. 160.

89 CaYrel P., Basilique donatiste, 1934, p. 140 ; Courcelle P., Ksar el-Kelb, 1936, p. 177. 
présente un tracé curieux, d'ailleurs conjectural, et aurait été construit lors d'un agrandissement de la sacristie sud. Tout au plus peut-on constater que ces installations, à caractère martyrial, viennent constituer dans le collatéral de l'église un second pôle de culte.

Dans l'église 4 d'Oued Rhezel, des reliques étaient conservées dans des récipients de terre cuite et de verre déposés dans "un massif maçonné fait de tuiles recouvertes de plâtre" (1,90 long x 1,80 m large x 0,60 m de haut) "à gauche du chœur" contre le mur d'abside 90 , et d'autres urnes reliquaires sont signalées contre le mur de soutènement de l'abside. L'ensemble n'est daté que par le matériel de fouille, abondant, qui remonterait aux ve$\mathrm{VI}^{\mathrm{e}}$ siècles, mais il est vraisemblable que la multiplicité des reliques indique des dépôts successifs dont certains doivent être postérieurs à l'époque d'Augustin.

Le dépôt des reliques découvertes dans l'abside de l'église d'Henchir Tarlist est tardif également. L'auge reliquaire de pierre $(0,95 \times 0,56$ x prof. $0,31 \mathrm{~m})$, enfouie à $40 \mathrm{~cm}$ sous le sol du presbyterium sous une dalle de plus de 2,00 m de long, comportait une inscription peinte sur le couvercle que la paléographie permet de dater de la seconde moitié du $\mathrm{VI}^{\mathrm{e}}$ siècle. La datation est confirmée par la mention, parmi les douze noms de martyrs, de plusieurs saints orientaux, dont le culte n'a été introduit en Afrique qu'avec la reconquête byzantine $^{91}$.

L'image qui ressort de l'étude des églises de Numidie à l'époque d'Augustin peut surprendre l'historien des textes. Les bâtiments qui peuvent avoir existé dès l'époque d'Augustin s'avèrent finalement peu nombreux si l'on tient compte des réserves émises plus haut sur les difficultés de datation. D'autre part, les hauts lieux liés à la vie d'Augustin Thagaste, Madaure et Hippone - ont finalement livré assez peu de vestiges chrétiens. La même déception guette l'historien qui chercherait à déceler dans les églises des traces archéologiques de l'action d'Augustin contre les donatistes et des luttes si virulentes que ces derniers ont suscitées en Numidie sous son épiscopat. Même si les listes conciliaires attestent dans de nombreuses localités l'existence d'une double hiérarchie, catholique et donatiste (cf. actes de la conférence de Carthage de 411), il est impossible, le plus souvent, d'identifier les édifices tenus par les donatistes. Rien, sur le plan archéologique - ni l'architecture, ni aménagements liturgiques particuliers - ne permet de différencier une église donatiste d'une église catholique. À Hippone même, on n'est pas capable de localiser la cathédrale donatiste à laquelle font allusion les sermons d'Augustin ${ }^{92}$. En Numidie, on ne possède qu'à deux reprises des indices qui suggèrent qu'on est en présence d'édifices donatistes, mais dans les deux cas, l'interprétation n'est finalement pas assurée. L'identification de l'église 7 de Timgad à la cathédrale donatiste ne repose finalement que sur une inscription trouvée dans le vestibule de la maison adjacente à l'édifice, qui

90 Berthier A., Logeart F., Martin M., Numidie Centrale, s. d. [1942], p. 57.

91 Duval Y., Loca sanctorum, I, $n^{\circ}$ 134, 1982, p. 281-283. On ne sait s'il faut retenir l'hypothèse proposée par LABROUSSE M., 1934, Henchir Tarlist, p. 257, selon laquelle le reliquaire correspondrait à des reliques cachées à la hâte dans le sol du presbyterium puisque le procès-verbal mentionne au moins douze noms de saints pour les six vases que renfermait le reliquaire ?

92 Cf. FÉVRIER P.-A., Approches du Maghreb romain, II, 1990, p. 28. 
mentionne un sacerdos Dei Optatus. On a voulu identifier ce personnage à l'évêque donatiste de Timgad ${ }^{93}$, mais l'emploi du terme sacerdos ne suffit pas pour y voir un évêque ${ }^{94}$. À Ksar el Kelb, la memoria conservée à l'extrémité du collatéral sud de l'église a été tenue pour celle du martyr donatiste Marculus, décédé en 347, mais l'identification reste débattue ${ }^{95}$. Quoi qu'il en soit, du point de vue archéologique, l'édifice ne présente aucun élément ni aménagement liturgique particulier qui permettrait de le distinguer d'une église catholique. Ce n'est guère d'ailleurs étonnant, puisque les querelles entre donatistes et catholiques portaient essentiellement sur le dogme et la légitimité du clergé et non sur les usages liturgiques, qui seuls laissent des traces dans les églises. L'analyse archéologique permet de restituer le cadre architectural dans lequel se déroulait la vie liturgique en révélant des aspects de la piété populaire dont les sources écrites et les réflexions d'Augustin ne dévoilent pas l'ampleur. Ainsi peut-on suivre, à travers la présence de tombes saintes, d'inhumations privilégiées, puis de dépôts de reliques, le développement du culte des saints et des martyrs et la ferveur qu'il suscita.

93 MandouZe A., Prosopographie, I, 1982, p. 797-801, surtout p. 799-800.

94 Gui I., Duval N., CAILlet J.-P., Basiliques de l'Algérie, 1992, p. 274-276.

95 Cf. Duval Y., Loca sanctorum, I, n 75 1982, p. 160. L'auteur, ibid., II, p. 705, semble accepter l'identification de Marculus, mais reste sceptique pour considérer les tombes de l'abside comme celles des compagnons du martyr donatiste. 


\section{ANNEXE \\ ÉLÉMENTS AVANCÉS POUR LA DATATION DES ÉDIFICES PRIS EN COMPTE}

Henchir Deheb [région de Kenchela-Tebessa] : le style des chapiteaux est attribué aux IV $\mathrm{V}^{\mathrm{e}}$ siècles, mais le type de plan avec le baptistère derrière l'abside remonte plutôt au $\mathrm{VI}^{\mathrm{e}}$ siècle - mais quelle est sa chronologie par rapport à l'église ?

Tébessa-Khalia 2 (triconque)[Numidie proconsulaire] : le style des éléments sculptés se rattache à celui de la basilique de Tébessa, d'où une datation au ve siècle.

Tébessa [Numidie Proconsulaire] : fin du IV siècle-début du ve siècle d'après un solidus de Théodose, daté de 388, et des comparaisons stylistiques des chapiteaux de la basilique avec ceux de la basilique Sud de Djemila traditionnellement datée de 441 (mais la date est controversée) et ceux de l'église de Bénian, datée par S. Gsell entre 434 et 439.

Morsott 1 : fin IVe-début ve siècle.

Madaure 2 : IV $\mathrm{I}^{\mathrm{e}} \mathrm{V}^{\mathrm{e}}$ siècles d'après le style des chapiteaux.

Madaure 3 : l'emplacement du chœur et probablement de l'autel très en avant dans la nef suppose une date antérieure à l'époque vandale.

Henchir Guesseria [région de Chemorra] : ve siècle d'après le style de la mosaïque.

Oued Rhezel 4 [région de Chemorra] : matériel de fouille attribué aux $\mathrm{V}^{\mathrm{e}}-\mathrm{VI}^{\mathrm{e}}$ siècles.

Seriana Pasteur 2 [région de Batna] : une inscription mentionne un évêque Argentius ; or on en connaît deux, l'un en 411, l'autre en 591.

Kherbet el Ousfane (Mechta et Tein) 2 [région de Bir Chouada] : d'après le style des piliers du chœur, Gsell date l'édifice de la seconde moitié du IVe siècle-début du ve siècle. L'église voisine $\left(n^{\circ} 1\right)$ serait assez tardive d'après l'emplacement de l'autel, proche de l'abside ; cependant le libellé de l'inscription martyrologique est assez ancien, malgré un tracé tardif selon DuVAL Y., Loca Sanctorum, I, 1982, p. 254.

Henchir Bou Takrematen [région de Bir Chouada] $v \mathrm{IV}^{\mathrm{e}}-\mathrm{V}^{\mathrm{e}}$ siècles pour la mensa marturum d'après la graphie de l'inscription.

Henchir el Atech [région d'Ä̈n Azel] : décor sculpté sur un claveau, attribué à la fin du IVe-début Ve siècle. 
Henchir Tarlist [région d'Ä̈n Azel] : milieu ou fin du ve siècle d'après le style des chapiteaux comparable à ceux de Tébessa et de la basilique de Bénian, datée entre 434 et 439, d'après LABROUSSE M., Henchir Tarlist, 1938, p. 255 et remaniements byzantins (paléographie de l'inscription du dépôt de reliques qui indique une date dans la seconde moitié du VIe siècle ou plus tard).

Et Toual [région de Biskra] : IV $\mathrm{V}_{-} \mathrm{V}^{\mathrm{e}}$ siècles sans argument précis (selon Delattre).

Djemila : église 1, IVe siècle, église II, ve siècle selon Albertini et Monceaux ; P.-A. Février pense que les deux églises sont contemporaines, et les date du ve siècle. Le pavement de l'église II remonterait au VIe siècle (pavement de Cresconius dans l'église Sud, tandis que celui de l'église Nord remonterait à la fin du IVe siècle). N. Duval n'est pas d'accord avec P.-A. Février ; cf. résumé dans GuI I., Duval N., CAILlet J.-P., Basiliques de l'Algérie, 1992, p. 93-94.

Djemila : Selon Allais Y., 1962-1965, Basilique cimétériale, p. 200-205 une ancienne memoria qui remonte au IVe siècle, et a ensuite été intégrée dans l'église. La date est avancée en fonction de la maçonnerie de la crypte, qui est très proche de celle de la basilique civile du nouveau forum érigé sous Valentinien et Valens entre 364 et 367. La crypte aurait été intégrée dans l'église à l'époque byzantine après la défaite des Vandales, au moment où la cité était appauvrie (à cause de la rusticité de la construction de l'église). DuVAL N. et FÉVRIER P.-A., Basilique cimétériale de l'Est, 1991, p. 73 ne sont pas d'accord et pensent que la construction de la crypte a été voulue avec l'église, car il existe d'autres cryptes à Djemila, mais ils ne donnent pas d'indications chronologiques.

Djemila, église Est : Dans la nef, une épitaphe à Pomponia Rusticula, clarissima femina, datée de 452 et trouvée hors contexte donne un terminus ante quem pour l'église.

Ksar $\boldsymbol{e l ~ K e l b}$ : IVe siècle selon les fouilleurs qui ne donnent pas de réel argument ; la datation est proposée d'après le style des fragments de décor architectural et l'identification de Marculus au martyr donatiste mort en 347. L'édifice est de toute façon antérieur à l'époque byzantine, car le fortin voisin, construit à cette période, remploie des éléments de l'église.

Timgad 1 : avant l'époque vandale, sans argument.

Timgad 7 : IVe siècle, de façon hypothétique d'après le style des chapiteaux. Il a existé un état byzantin. 


\section{BIBLIOGRAPHIE}

ALLAIS Y., 1962-1965, Une basilique cimétériale à Djemila (Cuicul), BAA, 1, p. 189-205.

Berthier A., LOgeart F., MARTin M., s. d. [1942], Les vestiges du christianisme en Numidie Centrale, Alger.

CAYRel P., 1934, Une basilique donatiste de Numidie, MEFR, 51, p. 114-142.

CHRISTERN J., 1976, Das frühchristliche Pilgerheiligtum von Tebessa, Wiesbaden.

CHRISTOFLE M., 1938, Rapport sur les travaux des fouilles et consolidations effectuées en 1933, 1934, 1935, 1936 par le Service des Monuments Historiques de l'Algérie, Alger, p. 356-477.

COURCELLE P., 1936, Une seconde campagne de fouilles à Ksar el-Kelb, MEFR, 52, p. 166-184.

Duval N., 1970, Les églises à deux absides d'Algérie. Analyse critique, Corso di cultura sull'arte ravennate e bizantina, 17 , p. 119-147.

Duval N., 1970, Les mosaïques funéraires chrétiennes d'Algérie, Corso di cultura sull'arte ravennate e bizantina, 17, p. 148-159.

Duval N. et FÉvrIER P.-A, 1972, Le décor des monuments chrétiens d'Afrique, Actas VIII CIAC, Barcelona, 5-11 octobre 1969, Cité du Vatican-Barcelone, p. 5-55, pl. I-XXVI.

Duval N., LAssus J., FÉVRIER P.-A., 1972, Groupes épiscopaux de Syrie et d'Afrique du Nord, Colloque Apamée de Syrie, p. 215-244.

Duval N., Sbeitla et les églises africaines à deux absides : recherches archéologiques sur la liturgie chrétienne en Afrique du Nord. 2, Inventaire des monuments, interprétation, Paris, 1973.

Duval N., 1981, Recherches archéologiques à Haïdra, II, La basilique I dite de Melléus ou de saint Cyprien, Rome.

Duval N. et JANON, M.,1985, Le dossier des églises d'Henchir Guesseria. Redécouverte du rapport Carbuccia (1849) et de l'aquarelle originale de la mosaïque : une fouille partielle en 1908 ?, MEFRA, 97, 2, p. 1095.

DuVAL N., 1986, "L'inhumation privilégiée"en Tunisie et en Tripolitaine, L'inhumation privilégiée du IVe au VIII siècle en Occident, Actes du colloque tenu à Créteil les 16/18 mars 1984, DUVAL Y. et PICARD J.-Ch. éds., Paris, p. 25-42.

Duval N. et FÉvrier P.-A., 1989, L'évêque et la cathédrale en Afrique du Nord, Actes XI ${ }^{e}$ CIAC, Lyon-Genève-Aoste, 1986, Paris-Rome, vol. I, p. 345-403.

Duval N., 1991, s. v. Basilique chrétienne africaine, Encyclopédie berbère, IX, Aix-en-Provence, p. 1371-1377.

Duval N. et FÉVRIER P.-A., 1991, Études d'Archéologie Chrétienne Nord-Africaine 20. La basilique cimétériale de l'Est à Djemila : une basilique à crypte méconnue, Aevum inter utrumque (Mélanges Sanders), Steenbruge-La Haye, p. 133-141.

Duval Y., 1982 Loca Sanctorum Africae. Le culte des martyrs en Afrique du IVe au VIIe siècle (coll. EFR, $\left.n^{\circ} 58\right)$, Rome.

Duval Y., 1984, Densité et répartition des évêchés dans les provinces africaines au temps de Cyprien, MEFRA, 96, p. 493-521.

FERDI S., 2001, Augustin de retour en Afrique. 388-430. Repères archéologiques dans le patrimoine algérien, Tipasa - Fribourg.

FÉVRIER, P.-A., 1965, Fouilles de Sétif. Les basiliques chrétiennes du quartier Nord-Ouest, Paris.

FÉVRIER P.-A., 1968, Nouvelles recherches dans la salle tréflée de Tébessa, BAA, III, p. 167-191. 
FÉVRIER P.-A., 1969, Travaux récents d'archéologie chrétienne en Algérie, Akten VII ${ }^{e}$ CIAC, Trier, 5 11 September 1965, Cité du Vatican-Berlin, p. 511-521, pl. CCXLIII-CCLXVIII ;

FÉVRIER P.-A., 1972, Travaux et découvertes en Algérie, Actas VIII ${ }^{e}$ CIAC, Barcelona, 5-11 octobre 1969, Cité du Vatican-Barcelone, p. 299-324, pl. CXX-CXXVII.

FÉVRIER P.-A., 1970, Le culte des martyrs en Afrique et ses plus anciens monuments, Corso di cultura sull'arte ravennate e bizantina, 17, p. 191-215.

FÉVRIER P.-A., 1972, Les sources épigraphiques et archéologiques et l'histoire religieuse des provinces orientales de l'Afrique antique, Corso di cultura sull'arte ravennate e bizantina, 19, p. 131158.

FÉVRIER P.-A., 1984, La tombe chrétienne et l'au-delà, Le temps chrétien de la fin de l'Antiquité au Moyen Age, III ${ }^{-}$-XIII ${ }^{e}$ siècles, Paris, 9-12 mars 1981, Paris, p. 163-183.

FÉVRIER P.-A., 1986, Tombes privilégiées en Maurétanie et en Numidie, L'inhumation privilégiée du IVe au VIII siècle en Occident, Actes du colloque tenu à Créteil les 16/18 mars 1984, DUVAL Y. et PICARD J.-Ch. éds., Paris, p. 13-23.

FÉvrIER P.-A., 1990, Approches du Maghreb romain, II, Aix-en-Provence.

GSELl St., 1901, Les monuments antiques de l'Algérie, Paris.

GSELL St., 1911, Atlas Archéologique de l'Algérie : texte et cartes, avec un texte explicatif, Alger.

Gui I., Duval N., Caillet J.-P., 1992, Basiliques chrétiennes d'Afrique du Nord (Inventaire et typologie), t. 1, Inventaire des monuments de l'Algérie, I. texte, II. Planches, Paris.

LABrousse M., 1938, Basilique et reliquaire d'Henchir Tarlist, MEFR, 55, p. 224-258.

LASSUS J., 1972, Questions sur l'architecture chrétienne de l'Afrique du Nord, Actas VIII CIAC, Barcelona, 5-11 octobre 1969, Cité du Vatican-Barcelone, p. 107-125, pl. XXXIV-XXXVII.

LANCEL S., 1982, À propos des nouvelles lettres de saint Augustin et la conférence de Carthage de 411 : cathedra, diocesis, ecclesia, parochia, plebs, populus, sedes, RHE, 77, p. 446-454.

LANCEL S., 1984, Études sur la Numidie d'Hippone au temps de saint Augustin. Recherches de topographie ecclésiastique, MEFRA, 96.2, p. 1085-1113.

LANCEL S., 1990, Évêchés et cités dans les provinces africaines, L'Afrique dans l'Occident romain (coll. EFR n ${ }^{\circ}$ 134), Rome p. 273-290.

LESCHI L., 1940, La basilique chrétienne en Algérie, Atti IVe CIAC, Rome 1938, Rome, p. 145-167 (= LESCHI L., 1957, Études d'épigraphie, d'archéologie et d'histoire africaines, Paris, p. 85-100).

Mandouze A., 1982, Prosopographie de l'Afrique Chrétienne (303-533), I, Paris.

MAREC E., 1958, Monuments chrétiens d'Hippone. Ville épiscopale de saint Augustin, Paris.

MARROU H.-I., 1960, La basilique chrétienne d'Hippone d'après les résultats des dernières fouilles, REAug, 6, p. 105-154.

MARrou H.-I., 1978, Survivances païennes dans les rites funéraires des donatistes, Christiana Tempora, Mélanges d'histoire, d'archéologie, d'épigraphie et de patristique (coll. EFR, n 35), Rome, 1978, p. 225-237 (= Hommages à J. Bidez et Fr. Cumont, coll. Latomus, II, s. d., p. 193-203).

MARrou H.-I., 1979, Une inscription chrétienne de Tipasa et le refrigerium, Ant.Afr., 14, p. 261-269.

MONCEAUX P., 1922, Découverte d'un groupe d'édifices chrétiens à Djemila, CRAI, p. 380-407.

Nussbaum O., 1965, Der Standort des Liturgen am christlichen Altar vor dem Jahre 1000, Bonn.

PERLER O., 1955, L'église principale d'Hippone et les autres sanctuaires chrétiens d'Hippone la Royale d'après les textes de saint Augustin, REAug, 1, p. 299-343.

Perler O., 1956, La memoria des Vingt Martyrs d'Hippone la Royale, REAug, 2, p. 435-446 (Mémorial G. Bardy).

SIMON M., 1934, Fouilles dans la basilique d'Henchir el Ateuch, MEFR, 51, p. 143-177. 